\title{
Long-term trends of temperature, salinity, density, and transient tracers in the central Greenland Sea
}

\author{
Gerhard Bönisch, ${ }^{1}$ Johan Blindheim, ${ }^{2}$ John L. Bullister, ${ }^{3}$ Peter Schlosser,${ }^{1,4}$ \\ and Douglas W. R. Wallace ${ }^{5}$
}

\begin{abstract}
We present long-term observations of temperature, salinity, tritium $/{ }^{3} \mathrm{He}$, chlorofluorocarbon-11 (CFC 11), and chlorofluorocarbon-12 (CFC 12) for the central Greenland Gyre. The time series span the periods between 1952 and 1994 (temperature), 1981 and 1994 (salinity), 1972 and 1994 (tritium/ ${ }^{3} \mathrm{He}$ ), and 1982 and 1994 (CFCs). The correlation between hydrographic and transient tracer data indicates that low temperatures in the deep water in the early 1950s and between 1960 and 1980 reflect periods of higher deep water formation rates whereas periods of increasing temperatures in the late 1950s and between 1980 and 1994 are related to low deep water formation rates. However, the transient tracer observations obtained in the 1980s and early 1990s indicate that even during periods of low deep water formation, some water from the upper water column contributed to deep water formation between 1980 and 1994. In 1994, the deep water reached temperatures and salinities of $-1.149^{\circ} \mathrm{C}$ and 34.899 , respectively, and no longer fits most of the classical definitions of Greenland Sea Deep Water $\left(-1.29^{\circ} \mathrm{C}<\Theta\right.$ $<-1.0^{\circ} \mathrm{C}, 34.88<\mathrm{S}<34.90$ ). The temperature increase in the water column between 200 and $2000 \mathrm{~m}$ depth between 1980 and 1994 corresponds to an average heating rate of about $5 \mathrm{~W} \mathrm{~m}^{-2}$ over this period, resulting in a decrease in density. The 13-year warming could be balanced by intensive cooling in two winters. The surface salinity steadily increased from 34.50 in 1991 to 34.85 in 1994 .
\end{abstract}

\section{Introduction}

Due to its large heat capacity and the exchange of heat between the ocean and the atmosphere, the ocean has a significant impact on climate. In the Atlantic, heat is transported from low latitudes northward, moderating the climate of Europe and North America. This northward heat transport is maintained by a return flow of colder deep water formed in the North Atlantic.

The Greenland Sea has long been recognized as an important region of deep water formation [e.g., Nansen, 1906; Aagaard et al.; 1985, Clarke et al., 1990; Schott et al., 1993]. The surface mixed layer of the central Greenland Sea starts to cool in fall, reaching temperatures

\footnotetext{
${ }^{1}$ Lamont-Doherty Earth Observatory of Columbia University, Palisades, New York.

${ }^{2}$ Institute of Marine Research, Bergen, Norway.

${ }^{3}$ Pacific Marine Environmental Laboratory, National Oceanographic and Atmospheric Administration, Seattle, Washington.

${ }^{4}$ Also at Department of Earth and Environmental Sciences, Columbia University, New York.

${ }^{5}$ Oceanographic and Atmospheric Sciences Division, Department of Applied Science, Brookhaven National Laboratory, Upton, New York.
}

Copyright 1997 by the American Geophysical Union.

Paper number 97JC00740.

0148-0227/97/97JC-00740\$09.00 near the freezing point in November or December [e.g., Visbeck et al., 1995]. Subsequent sea ice formation can increase the surface salinity due to brine release. Deepening of the mixed layer by about $1 \mathrm{~m}$ per day [Visbeck et al., 1995] leads to entrainment of heat and salt from underlying waters. Continued cooling from the surface eventually can induce deep convection which under favorable conditions may reach the bottom of the Greenland Sea. The density of the surface waters shows significant interannual variability, and in some years, convection does not extend below depths of a few hundred meters [Quadfasel and Meincke, 1987].

Recently, evaluation of time series of hydrographic and transient tracer data have provided evidence for decadal variability of the characteristics of Greenland Sea Deep Water (GSDW), which has been linked to changes in intensity of deep water formation [Clarke et al., 1990; Schlosser et al., 1991; Rhein, 1991; Meincke et al., 1992; Bönisch and Schlosser, 1995]. These studies focused on the deep water, rather than the temporal evolution of the properties throughout the entire water column, and did not simultaneously examine hydrographic and transient tracer data. They also did not attempt to examine the entire data set available for this region. The purpose of this study is to fill these gaps in the synthesis of Greenland Sea data and, in this context, to present new data obtained on four cruises between 1991 and 1994, which considerably add to our understanding of the decadal variability in the Greenland Sea. 


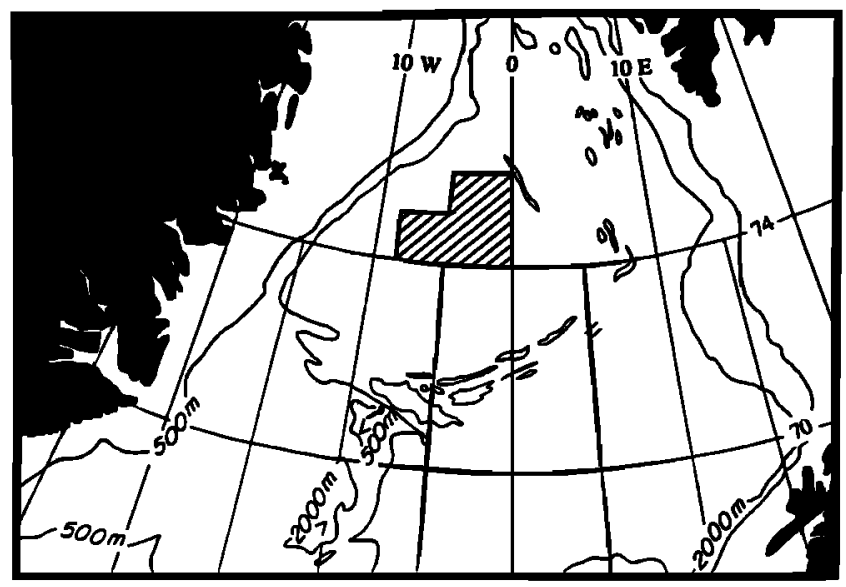

Figure 1. Map of the Greenland Sea; all stations used in this study are located in the hatched area.

\section{Description of the Data Set}

As part of this study, we evaluate previously unpublished data collected in the center of the Greenland Sea during four cruises of the Norwegian research vessel $\mathrm{Jo}$ han Hjort between 1991 and 1994. All Johan Hjort cruises were carried out in November. The center of the Greenland Gyre is defined as the area between 0 and $8^{\circ} \mathrm{W}$ in the southern sector $\left(74\right.$ to $\left.75^{\circ} \mathrm{N}\right)$ and between 0 and $5^{\circ} \mathrm{W}$ in the northern sector $\left(75\right.$ to $76^{\circ} \mathrm{N}$, Figure 1 [Kollermann and Lüthje, 1989]). We have restricted the selection of the stations to this area to minimize the influence of boundary effects. For evaluation of long-term trends, we combine our data collected during the 1990s with historical data from the same area. The stations used for this purpose are listed in Table 1. In the context of this study, long-term trends are defined as changes that occur on timescales of several years to decades. The amplitude of the seasonal cycle in the surface layer of the Greenland Sea is large. The data set presented here, collected at various times during the annual cycle over a number of years, is too sparse to adequately resolve the seasonal cycle or to detect systematic long-term trends in the surface layer over the study period.

A concern in identifying trends in oceanographic timeseries is the separation of temporal from spatial variability. Spatial variability in the temperature field in our restricted study area was evaluated by examining data from years in which multiple stations were occupied, covering a significant portion of the central Greenland Sea. Mean values, standard deviations, and $95 \%$ confidence intervals for all observations taken during a particular year in two narrow depth intervals $(900-1100 \mathrm{~m}$ and $2900-3100 \mathrm{~m}$ ) were calculated and are listed in Table 2. These depth intervals were chosen, because they are near the center of the intermediate and deep layers used for a quantitative evaluation in section 4 . The standard deviations of the mean values of the potential temperature are usually $<0.008^{\circ} \mathrm{C}$ in the deeper water column and $<0.03^{\circ} \mathrm{C}$ in the intermediate waters. For comparison, long-term trends of potential temperature that we identify are of the order of $0.08^{\circ} \mathrm{C}$ per decade in deep water and $0.2^{\circ} \mathrm{C}$ per decade in intermediate water. Therefore year to year changes cannot be addressed by the data set. On the other hand, long-term trends occurring on timescales of several years to decades are significantly larger than the uncertainties associated with the sometimes limited spatial sampling.

\subsection{Hydrographic Data}

Temperature and salinity data from the 1991 cruise of the Norwegian research vessel Johan Hjort were obtained using a Neil Brown conductivity-temperaturedepth sensor (CTD) with an underwater pressure sensor specified for a maximum pressure of $3000 \mathrm{dbar}$. Precision of the salinity data collected during this cruise was about \pm 0.002 . In 1992, a Neil Brown CTD with an underwater pressure sensor specified for 6000 dbar was used. Precision of the 1992 salinity data was about \pm 0.003 . In 1993 and 1994, a Seabird CTD with dual TC (temperature, conductivity) sensors was used. Precision of the 1993 and 1994 salinity measurements was about \pm 0.001 . For calibration purposes, bottle salinity samples from depths below $1000 \mathrm{~m}$ were analyzed on board Johan Hjort in 1991, 1992, and 1993 using a Portasal Model 8410 salinometer and onshore in 1994 using an Autosal Model $8400 \mathrm{~A}$ salinometer.

Precision of the temperature data was $\pm 0.001^{\circ} \mathrm{C}$ for all cruises. In 1991 and 1992, electronic SIS reversing thermometers were used to control the CTD (no correction was applied to the CTD data).

The first temperature and salinity data from the Greenland Sea date back to the beginning of the century. The quality of these measurements, however, is unclear. For this reason, we start our temperature time series in 1952 and the salinity time series in 1981 . We have to restrict the salinity time series to the 1980 s, because the small changes in salinity (less than 0.01 ) are comparable to the noise level of most of the earlier data sets. At least one early survey, however, the 1972 Geochemical Ocean Sections Study (GEOSECS) data, has the required data quality. Since the gap between 1972 (GEOSECS) and 1981 (Transient Tracers in the Ocean/North Atlantic Study (TTO/NAS)) is too large for an adequate interpolation, the GEOSECS salinities are only used as a reference for conditions in the early 1970s. In general, it is difficult to detect the small year to year changes in salinity that occur in the deep water even with modern techniques, and intercalibration uncertainties of a few parts per million are difficult to exclude. However, the quality of the data is sufficiently high to show long-term trends in salinity during the 1980 s and early 1990 s.

In contrast, temperature data since 1952 have the precision and accuracy required to resolve the observed changes which are of the order of $0.1^{\circ} \mathrm{C}$. The main source of the historical temperature and salinity data used in this study is the NODC data CD ROM [ $\mathrm{Na}$ tional Oceanographic Data Center, 1991]. We used only the Nansen bottle cast data, because these are of the 


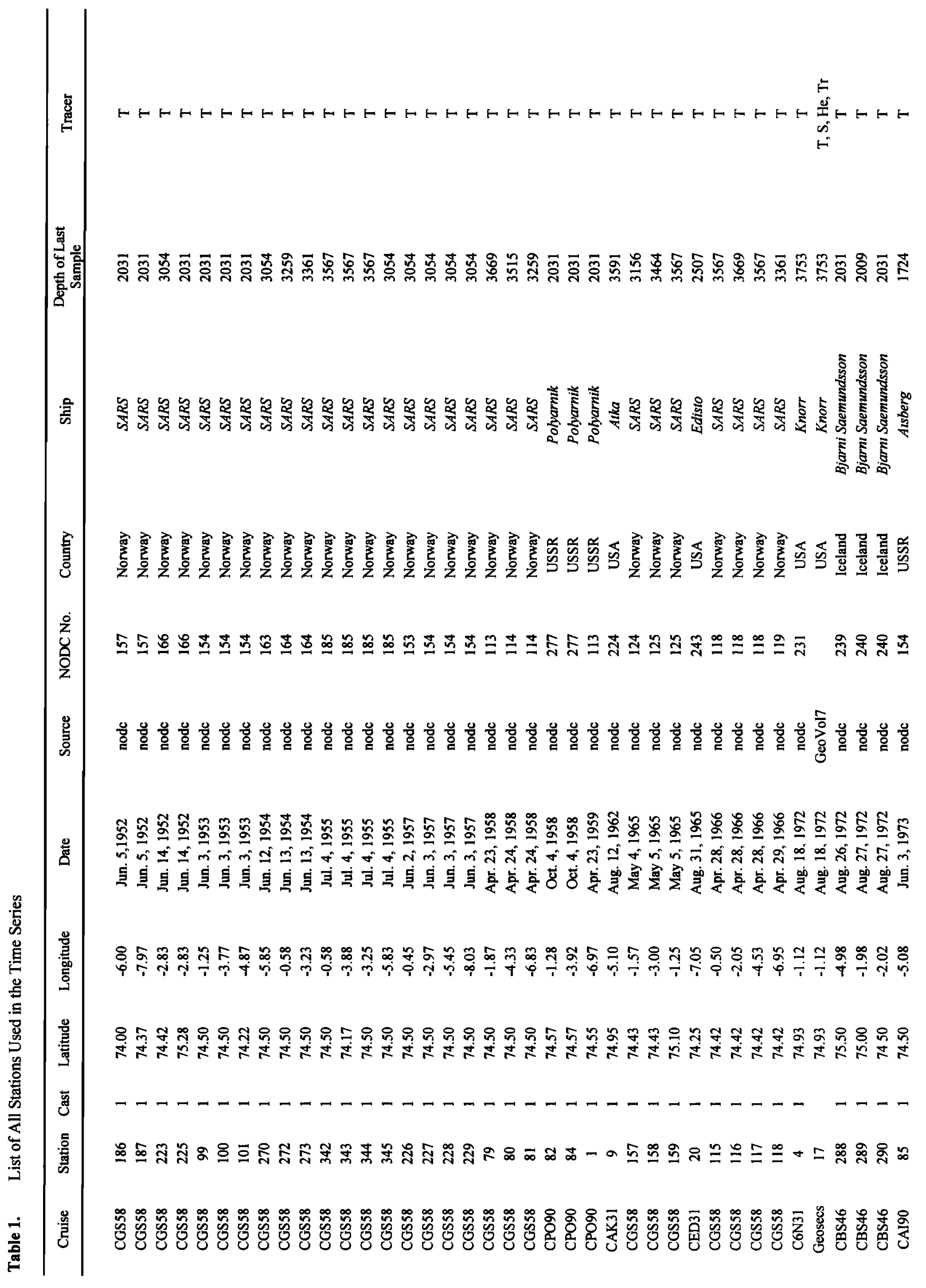




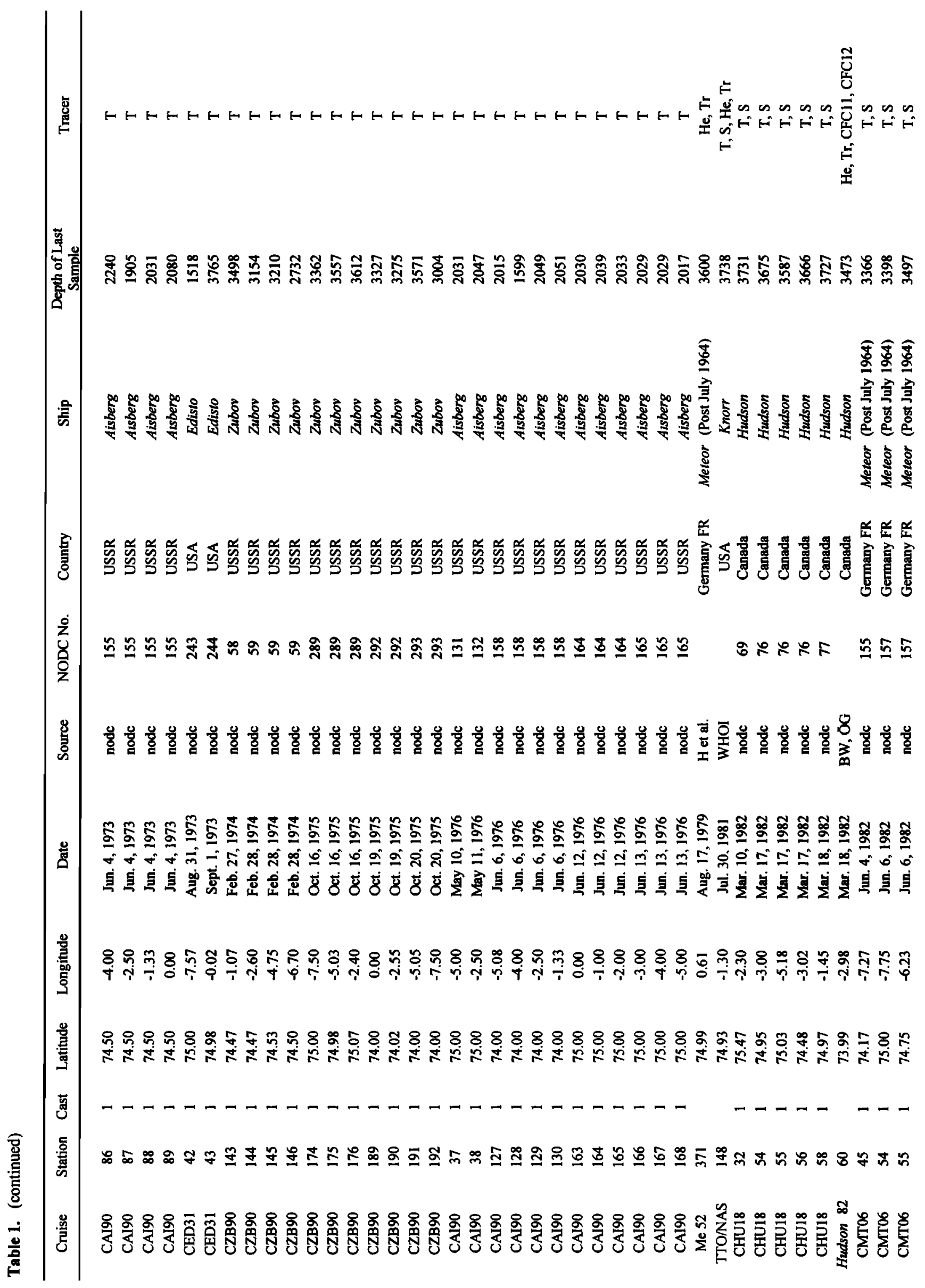




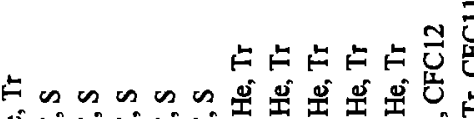

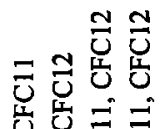

권류

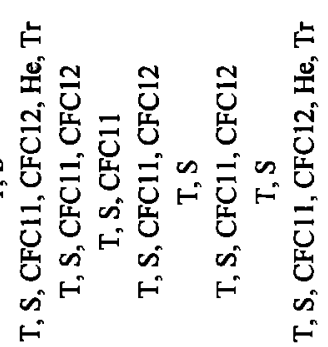

苟

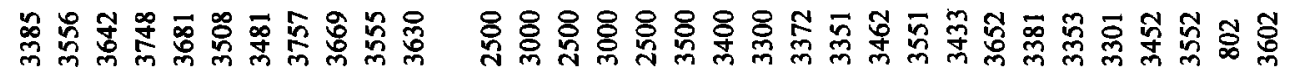

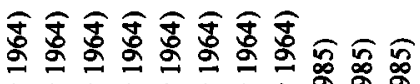

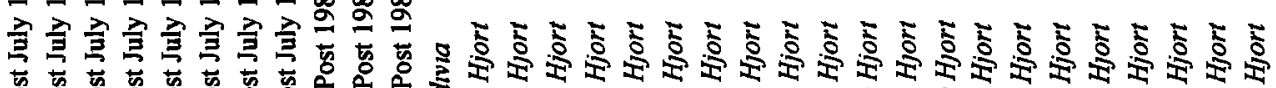

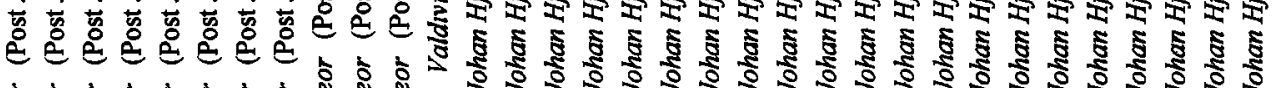

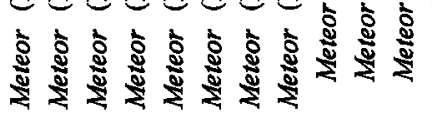

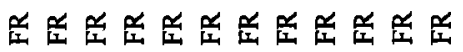

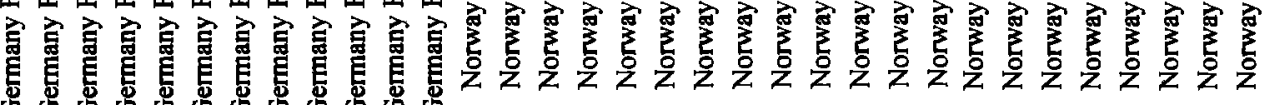

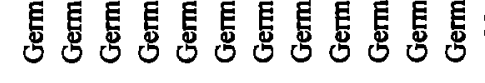

$\stackrel{\infty}{n} \stackrel{\infty}{2} \stackrel{0}{0} \stackrel{\infty}{0}$

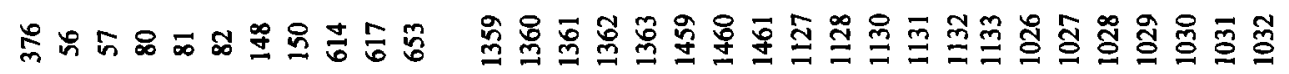

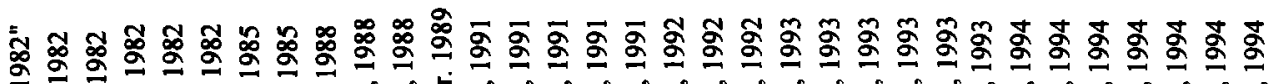

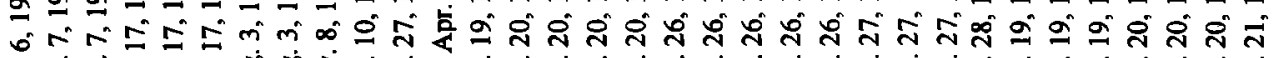

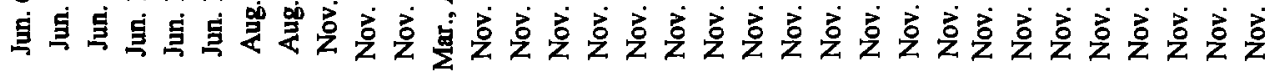

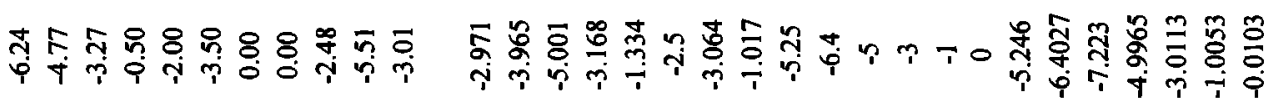

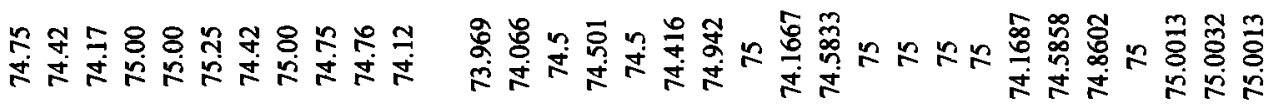

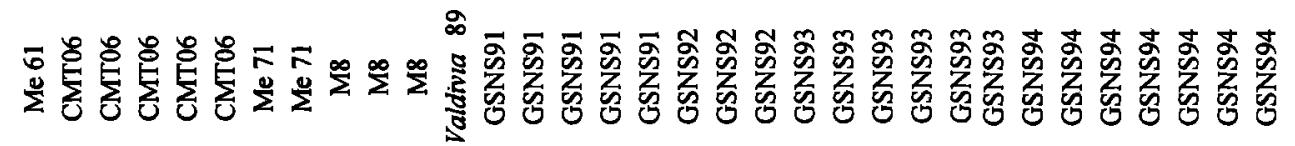

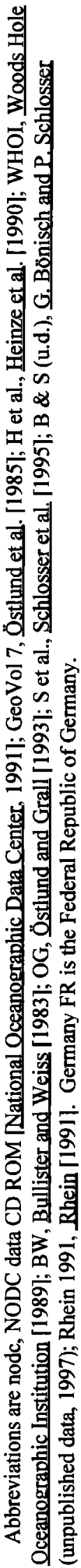


Table 2. Mean Values, Standard Deviations, and $95 \%$ Confidence Intervals of Temperature Observations Between 900 and $1100 \mathrm{~m}$ and Between 2900 and $3100 \mathrm{~m}$ Depth From Years in Which Three or More Stations Were Occupied and Contained Observations in the Appropriate Depth Intervals

\begin{tabular}{|c|c|c|c|c|c|c|c|}
\hline Year & $\begin{array}{c}\begin{array}{c}\text { Number } \\
\text { of } \\
\text { Stations }\end{array} \\
\end{array}$ & $\begin{array}{l}\text { Number of } \\
\text { Institutions }\end{array}$ & Depth Interval & $\begin{array}{l}\text { Number of } \\
\text { Observations }\end{array}$ & Mean & Std Dev & $\begin{array}{c}95 \% \\
\text { Confidence } \\
\text { Interval } \\
\end{array}$ \\
\hline \multirow[t]{2}{*}{1955} & 4 & 1 & $900-1100 m$ & 4 & -1.188 & 0.03 & 0.029 \\
\hline & & & $2900-3100 \mathrm{~m}$ & 4 & -1.256 & 0.008 & 0.008 \\
\hline \multirow[t]{2}{*}{1957} & 4 & 1 & $900-1100 m$ & 4 & -1.012 & 0.009 & 0.008 \\
\hline & & & $2900-3100 m$ & 4 & -1.249 & 0.005 & 0.005 \\
\hline \multirow[t]{2}{*}{1966} & 4 & 1 & $900-1100 m$ & 4 & -1.208 & 0.019 & 0.018 \\
\hline & & & $2900-3100 \mathrm{~m}$ & 4 & -1.249 & 0.008 & 0.008 \\
\hline \multirow[t]{2}{*}{1972} & 5 & 3 & $900-1100 m$ & 4 & -1.101 & 0.033 & 0.032 \\
\hline & & & $2900-3100 m$ & 4 & -1.315 & 0.002 & 0.001 \\
\hline \multirow[t]{2}{*}{1975} & 7 & 1 & $900-1100 m$ & 3 & -1.124 & 0.029 & 0.033 \\
\hline & & & $2900-3100 \mathrm{~m}$ & 4 & -1.277 & 0.012 & 0.012 \\
\hline \multirow[t]{2}{*}{1982} & 15 & 2 & $900-1100 m$ & 13 & -1.141 & 0.028 & 0.015 \\
\hline & & & $2900-3100 \mathrm{~m}$ & 9 & -1.274 & 0.005 & 0.003 \\
\hline \multirow[t]{2}{*}{1991} & 5 & 1 & $900-1100 m$ & 5 & -0.968 & 0.045 & 0.039 \\
\hline & & & $2900-3100 m$ & 2 & -1.196 & 0.003 & 0.003 \\
\hline \multirow[t]{2}{*}{1992} & 3 & 1 & $900-1100 \mathrm{~m}$ & 3 & -0.863 & 0.02 & 0.022 \\
\hline & & & $2900-3100 \mathrm{~m}$ & 3 & -1.186 & 0.001 & 0.001 \\
\hline \multirow[t]{2}{*}{1993} & 6 & 1 & $900-1100 \mathrm{~m}$ & 3 & -0.944 & 0.089 & 0.100 \\
\hline & & & $2900-3100 m$ & 3 & -1.181 & 0.003 & 0.003 \\
\hline \multirow[t]{2}{*}{1994} & 7 & 1 & $900-1100 \mathrm{~m}$ & 6 & -0.868 & 0.046 & 0.037 \\
\hline & & & $2900-3100 \mathrm{~m}$ & 5 & -1.163 & 0.005 & 0.005 \\
\hline
\end{tabular}

highest quality. Stations which did not reach a depth of at least $1500 \mathrm{~m}$ were omitted from this study. Also omitted were data points below $1500 \mathrm{~m}$ which fell off a mean profile constructed for each individual cruise by more than $2 \sigma\left(1 \sigma: 0.01^{\circ} \mathrm{C}\right.$ and 0.003 for temperature and salinity, respectively).

\subsection{Tracer Data}

In addition to temperature and salinity, we examined the evolution of the tritium $/{ }^{3} \mathrm{He}$ and CFC distributions in the central Greenland Sea. Tracer data were collected during all Johan Hjort cruises and on several other cruises between 1972 and 1989. During the Johan Hjort cruises, water samples for analysis of CFCs and tritium $/{ }^{3} \mathrm{He}$ were collected from 5 -L Niskin bottles. The Niskin bottles were designed for low CFC background.

Tritium is the radioactive isotope of hydrogen and decays with a half-life of 12.43 years to ${ }^{3} \mathrm{He}$ [Unterweger et al.,1980]. Most of the tritium presently observed in the environment has been produced during the atmospheric nuclear weapon tests in the 1950s and early 1960s. Atmospheric concentrations reached maximum values during the mid 1960 s and have been decreasing since. Tritium enters the ocean via precipitation, water vapor exchange, and river runoff as tritiated water
(HTO) [e.g., Weiss and Roether, 1980]. Tritium concentrations are reported in TU, where $1 \mathrm{TU}$ means a tritium to hydrogen ratio of $10^{-18}$. In the TU81 notation, the tritium concentrations are decay corrected to the date of January 1, 1981.

Helium 3 and helium 4 in the ocean originate from the atmosphere, the mantle, the crust, and tritium decay (for separation of the different components, see, e.g., Schlosser [1992]). Usually, ${ }^{3} \mathrm{He}$ data are reported in the $\delta$ notation, i.e., the percent deviation of the ${ }^{3} \mathrm{He} /{ }^{4} \mathrm{He}$ ratio of a sample from that of air $\left(1.384 \times 10^{-6}\right.$ [Clarke et al., 1976]).

Simultaneous tritium and ${ }^{3} \mathrm{He}$ measurements allow us to calculate the tritium $/{ }^{3} \mathrm{He}$ age

$$
\tau=\frac{\mathrm{T}_{1 / 2}}{\ln 2} \ln \left(1+\frac{\left[{ }^{3} \mathrm{He}_{\mathrm{trit}}\right.}{\left[{ }^{3} \mathrm{H}\right]}\right)
$$

where $T_{1 / 2}$ is the half life of tritium and $\left[{ }^{3} \mathrm{He}\right]_{\text {trit }}$ and $\left[{ }^{3} \mathrm{H}\right]$ are the tritiogenic ${ }^{3} \mathrm{He}$ and tritium concentrations, respectively (in TU). Samples for He isotope and tritium analysis were collected in $40-\mathrm{mL}$ copper tubes sealed by stainless steel pinch-off clamps. Additional tritium samples were stored in 1-L glass bottles. Tritium samples were degassed onshore using a high vacuum extraction system and stored in special glass 
bulbs with low He permeability for ingrowth of tritiogenic ${ }^{3} \mathrm{He}$. Helium-3 grown in from tritium decay over a period of typically 6 months was measured on a commercial VG 5400 mass spectrometer with a specially designed inlet system [Ludin et al., 1997]. Helium isotope samples were extracted using the same extraction system and measured on the same mass spectrometric system. Precision of the $\delta^{3} \mathrm{He}$ data was $\pm 0.2 \%$; precision of the tritium data was $\pm 2 \%$ or \pm 0.02 TU. Tritium and $\mathrm{He}$ isotope measurement procedures used in the Lamont-Doherty Earth Observatory (LDEO) noble gas laboratory are described in detail by Ludin et al. [1997].

Pre-industrial atmospheric concentrations of CFC 11 and CFC 12 were zero. Since the start of industrial CFC production in the 1930s, their atmospheric concentrations have steadily increased. Relative growth rates of CFC 11 and CFC 12 in the atmosphere were different until the mid 1970s but have been practically identical since then. CFCs enter the ocean via gas exchange with the atmosphere. CFCs were measured on board using purge-and-trap gas chromatography with electron capture detection. A Varian $\mathbf{3 3 0 0}$ gas chromatograph was used, together with a custom-built purgeand-trap apparatus similar to that described by Wallace et al. [1994] and more completely by Happell et al. [1996]. Calibration was achieved by injections of known amounts of a working standard with known concentrations of CFC 11 and CFC 12 [Happell and Wallace, 1997]. All results are reported relative to the Scripps Institute of Oceanography (SIO) 1986 calibration scale [Cunnold et al., 1994]. After subsampling the 5-L Niskin bottles, CFC samples were stored in 100 or 50-mL glass syringes under surface seawater prior to analysis. Accuracy of the analyses relative to the SIO calibration scale was about $\pm 2 \%$.

\section{Time Series}

Plate 1 presents the temporal evolution of potential temperature, salinity, density $\left(\sigma_{2}\right)$, tritium, $\delta^{3} \mathrm{He}$, the tritium $/{ }^{3} \mathrm{He}$ age, CFC 11 , and CFC 12 as time-depth sections throughout the entire water column. The frequency of cruises to the Greenland Sea varied over time, as did the number of stations occupied during the individual years. The data used to produce Plate 1 were gridded with a time step of 3 months and a depth interval of $25 \mathrm{~m}$. The depth intervals and time periods without observations were linearly interpolated. Finally, the interpolated fields were smoothed by averaging each point with its eight closest data points.

\subsection{Temperature}

The temperature time series extends from 1952 to the end of 1994 . Below $2000 \mathrm{~m}$, we find clear evidence for decadal variability as noted earlier by Clarke et al. [1990]. We observe two relatively warm periods, the first between 1955 and 1965 and the second lasting from 1982 until the end of the time series. In contrast to these warm periods, the temperature of the deep water in the
Greenland Sea was low during the early $1950 \mathrm{~s}\left(-1.25^{\circ} \mathrm{C}\right.$ $\left.>\Theta>-1.3^{\circ} \mathrm{C}\right)$ and in the $1970 \mathrm{~s}\left(\Theta<-1.3^{\circ} \mathrm{C}\right)$. During the 1980 s and early 1990 s, the temperatures increased steadily, exceeding $-1.2^{\circ} \mathrm{C}$ at the end of 1994 . The indication of a similar warming trend during the early 1960 s is strongly dependent on a single data point ( $A t k a$ cruise $1962,3027 \mathrm{~m}$ ) and is discussed in detail below.

In the depth range between 200 and $2000 \mathrm{~m}$, the variations are more complex. Between 1985 and 1994, this layer warmed monotonically, as indicated by the deepening of the $-1.0^{\circ} \mathrm{C}$ isotherm from $200 \mathrm{~m}$ in 1985 to $1700 \mathrm{~m}$ in 1994 . Similar warming trends occurred between 1954 and 1959 and between 1973 and 1976. The latter warming events, however, were neither as pronounced nor as long-lived as the one presently observed. The presence of cold upper Arctic Intermediate Water $\left(2^{\circ} \mathrm{C}>\Theta>-1.8^{\circ} \mathrm{C} ; 34.7<\mathrm{S}<34.9\right.$ [Swift and Aagaard, 1981]) is visible several times as a temperature minimum at about $200 \mathrm{~m}$ in Plate 1 a. As noted earlier, surface temperature trends cannot be addressed in this study due to data limitations.

\subsection{Salinity}

During the early 1980s, the water observed in the Greenland Sea below $1700 \mathrm{~m}$ depth had salinities of about 34.890 (Plate $1 \mathrm{~b}$ ). Between 1981 and 1994, the salinity increased monotonically. The deep water reached salinities of 34.895 in 1989 and 34.900 in late 1994 . In the depth range between 1200 and $1700 \mathrm{~m}$, salinity changes were small with values between 34.890 and 34.895 without showing a clear trend. The boundary of the low salinity water ( $\mathrm{S}<34.880$ ) found in the upper part of the water column deepened between 1989 and 1994 from 150 depth to $950 \mathrm{~m}$ depth, respectively. Again, there are not enough observations to address the seasonally variable surface water. However, since 1988 , all the observations available to us were collected during the month of November and can therefore be compared. This comparison indicates an increase of surface (between 0 and $25 \mathrm{~m}$ depth) salinity between 1991 and 1994 from 34.50 to 34.85 , respectively.

\subsection{Density}

Because our study is focused on changes in the intermediate and deep Greenland Sea, we use $2000 \mathrm{dbar}$ as the reference level for the density time series (Plate $1 \mathrm{c}$ ). The $\sigma_{2}=37.45$ isopycnal deepened steadily from $550 \mathrm{~m}$ depth in 1981 to $2000 \mathrm{~m}$ depth in 1994 . A density difference of 0.1 (37.33 to 37.43 ) occurred within a depth interval of only $100 \mathrm{~m}$ (between 100 and $200 \mathrm{~m}$ ) in 1981 . In 1994, this difference is spread over a water column of $850 \mathrm{~m}$ (between 400 and $1250 \mathrm{~m}$ depth), indicating a density decrease in this part of the water column. Below $2000 \mathrm{~m}$, the density remained almost unchanged between 1981 and 1994.

\subsection{Tritium $/{ }^{3} \mathbf{H e}$}

The first tritium/He data from the center of the Greenland Gyre were collected during GEOSECS in 
1972 [Östlund et al., 1987]. These data, together with subsequent surveys in 1979 (Me 52 [Heinze et al., 1990]), 1981 (TTO/NAS [Woods Hole Oceanographic Institution, 1989; Smethie et al., 1986]), 1982 (Me 61 [Heinze et al., 1990]; Hudson 82 [Östlund and Grall, 1993]), 1985 (Me 71 [Schlosser et al., 1995]), and 1988 (M 8 [Bönisch and Schlosser, 1995]), and the Johan Hjort cruises form the longest transient tracer time series for the central Greenland Sea. Tritium concentrations in surface waters decrease from nearly $5 \mathrm{TU}$ in 1972 to $1.9 \mathrm{TU}$ in 1994 (Plate $1 \mathrm{~d}$ ). In the depth range between 750 and $1500 \mathrm{~m}$, tritium concentrations changed little over this time period. Tritium concentrations below $1500 \mathrm{~m}$ remained nearly constant during the 1970 s. The GEOSECS tritium measurements show a relatively large scatter compared to the more recent data. Tritium values in the deep water $(>2000 \mathrm{~m}$ ) ranged from 1.1 to $1.7 \mathrm{TU}$, without a significant depth gradient. The Me 52 data in 1979 and the surveys in the early 1980s (TTO/NAS 1981; Me 61 and Hudson 82, 1982) also show relatively high tritium concentrations ( $>1.0 \mathrm{TU})$ in the deep water, but with less scatter. The data obtained in the mid 1980s (Me 71, 1985) and in the late 1980s (M 8, 1988) show lower tritium concentrations. This trend continued during the Johan Hjort cruises in the early 1990s; in 1994, tritium concentrations of the deep water reached values below $0.6 \mathrm{TU}$.

With the exception of the Hudson 82 cruise, He isotope data were obtained simultaneously with the tritium data (Plate $1 \mathrm{e}$ ). The tritium $/{ }^{3} \mathrm{He}$ age time series (Plate $1 \mathrm{f}$ ) is established by combining the tritium and tritiogenic ${ }^{3} \mathrm{He}$ data according to (1). Because of gas exchange with the atmosphere, surface $\delta^{3} \mathrm{He}$ values are close to solubility equilibrium with the atmosphere $(-1.8 \%$, [Benson and Krause, 1980]) and the tritium $/{ }^{3} \mathrm{He}$ age is close to zero. An intermediate $\delta^{3} \mathrm{He}$ maximum found in most regions of the oceans in the northern hemisphere indicating the penetration depth of tritium [e.g., Schlosser et al., 1995] is completely missing in the central Greenland Sea. Instead, we observe monotonically increasing $\delta^{3} \mathrm{He}$ values between the surface and the deep water. Both $\delta^{3} \mathrm{He}$ values and tritium $/{ }^{3} \mathrm{He}$ ages show the lowest values below $3000 \mathrm{~m}$ depth during the $1970 \mathrm{~s}$. During the 1980 s and early $1990 \mathrm{~s}, \delta^{3} \mathrm{He}$ values increase from about $3 \%$ (1981) to $6 \%(1994)$, and the tritium $/{ }^{3} \mathrm{He}$ ages increase from about 12 years in 1981 to about 25 years in 1994 . Over 13 calendar years, the tritium $/{ }^{3} \mathrm{He}$ age of this part of the deep water increased by 13 years, suggesting that this water body was completely isolated from exchange with young waters between 1981 and 1994. However, a more detailed examination in section 4 shows that this was not the case.

\subsection{CFCs}

The first CFC 11 and CFC 12 measurements originate from 1982 (Hudson 82 cruise [Bullister and Weiss, 1983; D.W.R. Wallace, unpublished data, 1985]). The only other CFC data set collected during the 1980s was reported by Rhein [1991] (Valdivia 1989 data).
CFC 11 and CFC 12 were measured during all Johan Hjort cruises between 1991 and 1994. Due to analytical problems, CFC 12 data are not available from the 1991 cruise. The time series of both CFCs show roughly the same features (Plates $1 \mathrm{~g}$ and $1 \mathrm{~h}$ ). At the surface, the concentrations increase from $4.2 \mathrm{pmol} \mathrm{kg}^{-1}$ (CFC 11) and $1.9 \mathrm{pmol} \mathrm{kg}^{-1}$ (CFC 12) in 1982 to $6.6 \mathrm{pmol} \mathrm{kg}^{-1}$ (CFC 11) and $3.1 \mathrm{pmol} \mathrm{kg}^{-1}$ (CFC 12) in 1994, due to the increasing atmospheric CFC concentrations. CFC concentrations of intermediate waters show a similar trend. Below $2250 \mathrm{~m}$ depth, CFC 12 remained practically constant $\left(0.39 \mathrm{pmol} \mathrm{kg}^{-1}\right.$ in $1982 ; 0.42 \mathrm{pmol} \mathrm{kg}^{-1}$ in 1994). The $0.8 \mathrm{pmol} \mathrm{kg}^{-1}$ isoline (CFC 11) deepened from $2600 \mathrm{~m}$ in 1989 to about $3300 \mathrm{~m}$ in the early $1990 \mathrm{~s}$, suggesting a very slight increase of the CFC 11 concentration. Below about $3300 \mathrm{~m}$, no significant CFC 11 concentration difference between 1982 and 1994 was observed.

\section{Discussion}

In discussing the observed temporal changes, we arbitrarily separate the water column into deep (below $2000 \mathrm{~m}$ ), intermediate $(200-2000 \mathrm{~m})$, and near-surface (above $200 \mathrm{~m}$ ) waters. The choice of $2000 \mathrm{~m}$ as the upper boundary of the deep layer is primarily based on tracer profiles, in particular on the location of the base depth of the exponentially decreasing tracer concentrations (Plates $1 \mathrm{~d}, \mathrm{~g}$, and $\mathrm{h}$ ). Furthermore, $2000 \mathrm{~m}$ is the approximate sill depth of the ridge separating the Greenland from the Norwegian Sea [Bourke et al., 1993]. The upper $200 \mathrm{~m}$ are strongly affected by exchange with the atmosphere and show seasonal effects.

In the following, we have chosen not to discuss specific water masses, such as Greenland Sea Deep Water, because these are defined in terms of specific temperature and salinity characteristics. One purpose of this contribution is to point out that these characteristics are variable in time. For example, GSDW has been defined as water with temperatures between -1.26 and $-1.29^{\circ} \mathrm{C}$ and salinities between 34.889 and 34.892 by Swift et al. [1983], temperatures below $-1.0^{\circ} \mathrm{C}$, and salinities between 34.88 and 34.90 by Aagaard et al. [1985], temperatures of $-1.28^{\circ} \mathrm{C}$ and salinities of 34.891 by Smethie et al. [1986], and temperatures of $-1.242^{\circ} \mathrm{C}$ and salinities of 34.895 by Swift and Koltermann [1988]. By the end of 1994, the water found in the center of the Greenland gyre below $2000 \mathrm{~m}$ depth had a temperature of $-1.149^{\circ} \mathrm{C}$ and a salinity of 34.899 , that is, it can no longer be identified as GSDW according to most of the above definitions.

\subsection{Deep Water (2000 m - Bottom)}

4.1.1. Temporal changes. To summarize trends in the deep water, we calculated the mean values of the gridded hydrographic and transient tracer data in the depth range between $2000 \mathrm{~m}$ and the bottom (Figure 2. The $1 \sigma$ standard deviations of these mean values are also indicated in Figure 2. These deviations do not include intercalibration uncertainties which are un- 


\section{Theta in the central Greenland Sea rs. time}

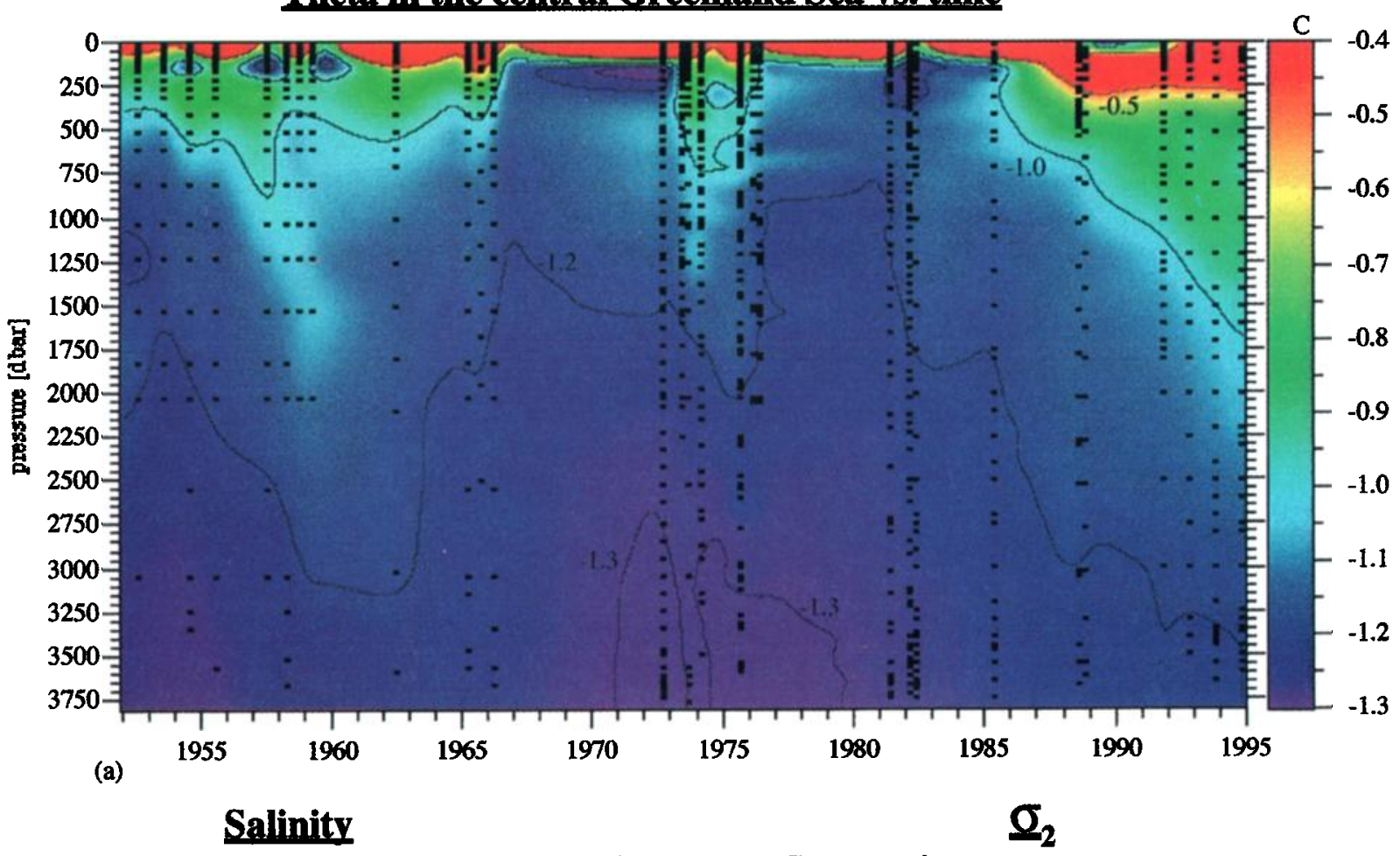

in the central Greenland Sea vs, time
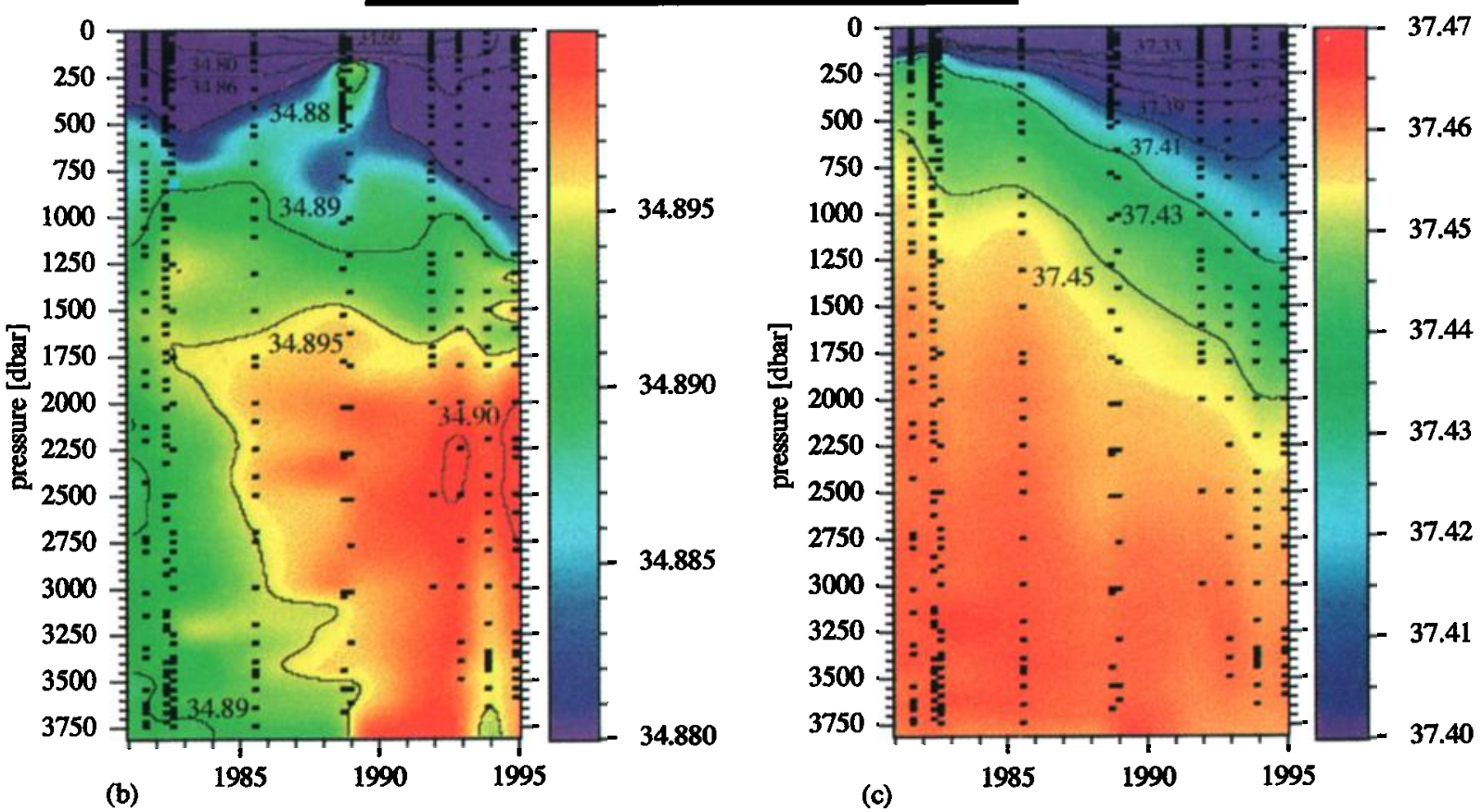

Plate 1. Time series of (a) $\Theta$, (b) salinity, (c) $\sigma_{2}$, (d) tritium, (e) $\delta^{3} \mathrm{He}$, (f) tritium $/{ }^{3} \mathrm{He}$ age, (g) CFC 11, and (h) CFC 12 in the central Greenland Sea. The time series are presented as sections with time as the horizontal axes and depth as the vertical axes. The color bars are chosen to reflect changes in the deep water. Each year marker indicates the first of January of the particular year. 

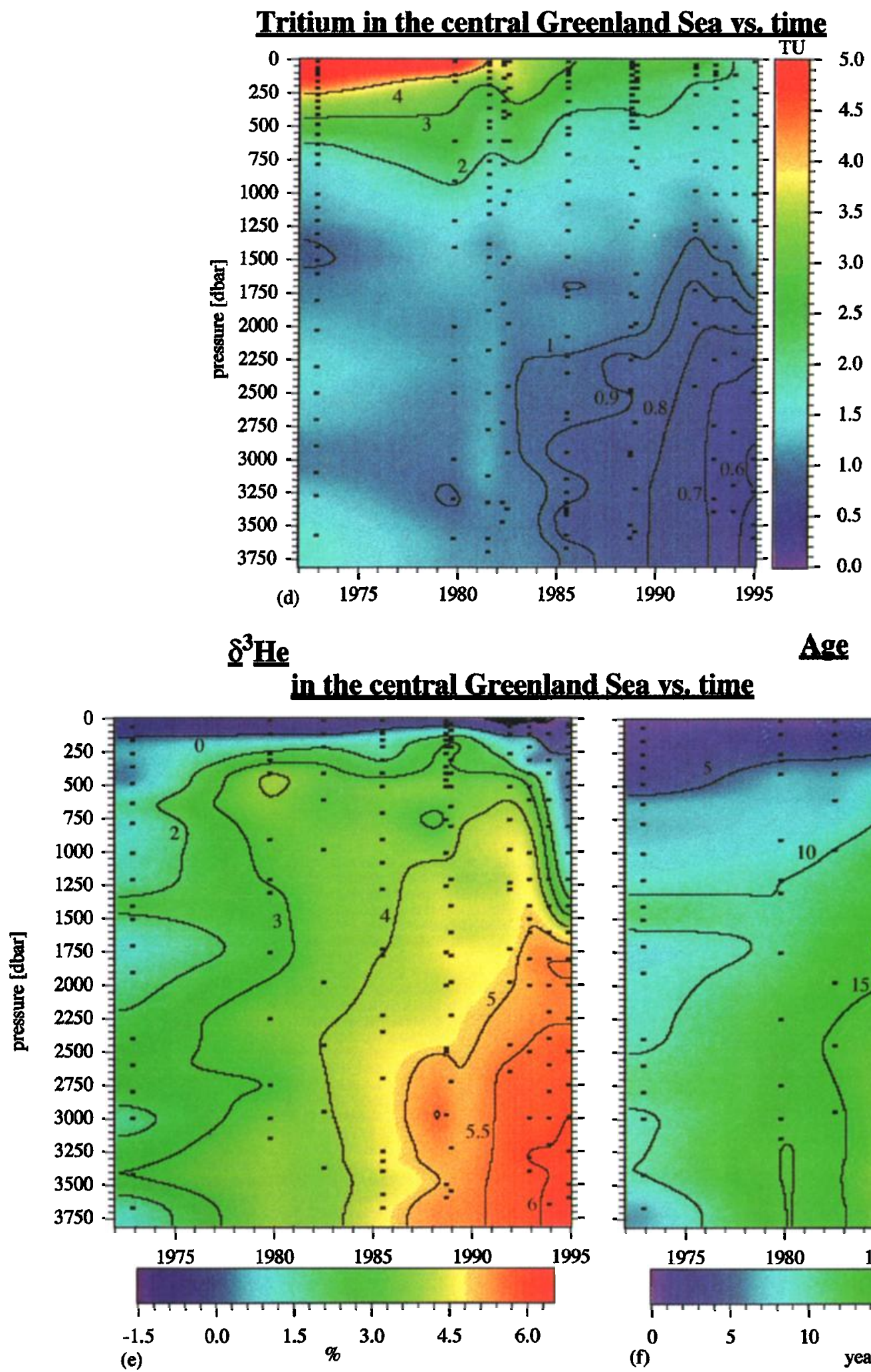

Age

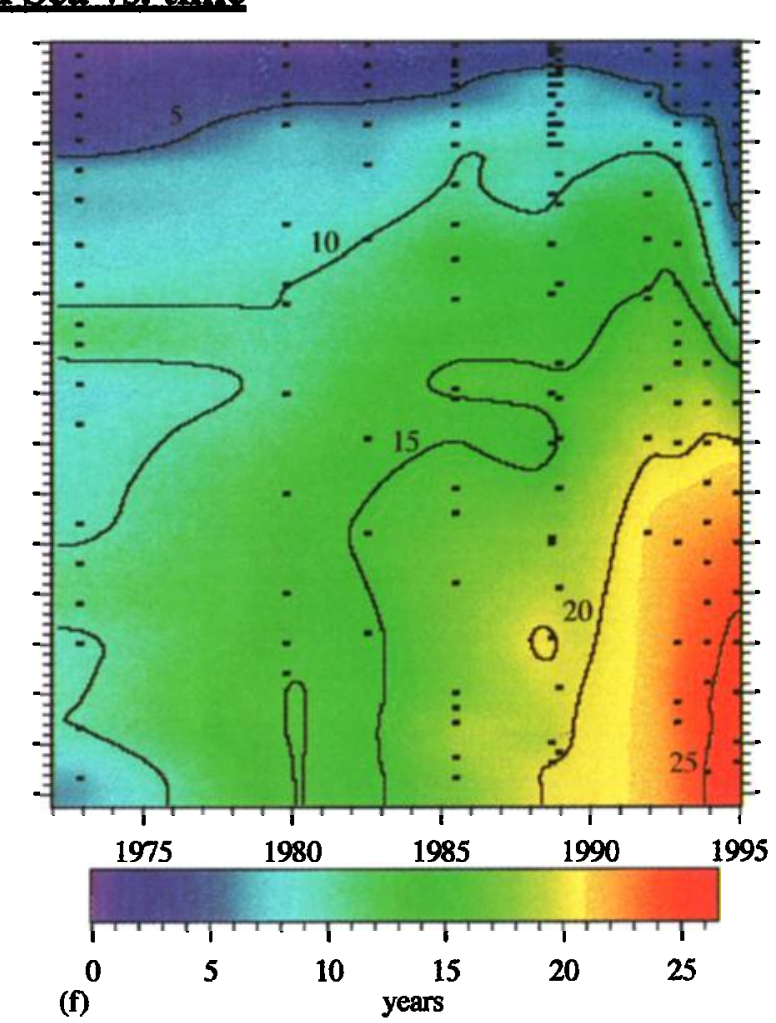

Plate 1. (continued) 


\section{CFC 11 CFC 12}

in the central Greenland Sea vs, time
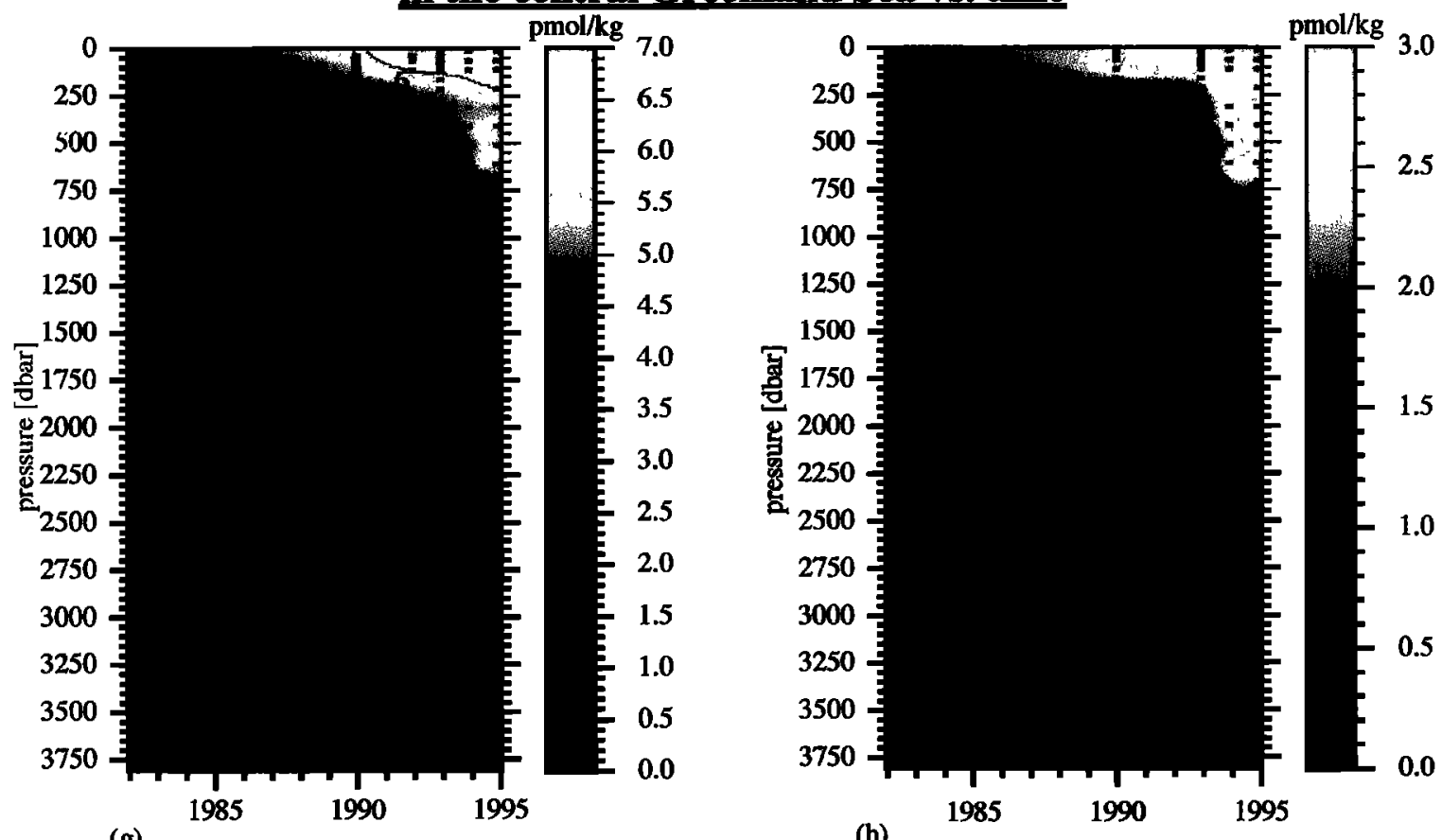

Plate 1. (continued)

likely to be significant compared to the observed standard deviations (see Table 2 for years in which data were collected on multiple cruises by different institutions). Where available, updated box-model-based simulations of the evolution of the transient tracer concentrations [Bönisch and Schlosser, 1995] are plotted together with the observed data in Figure 2. In all plots, two different model simulations are presented. One scenario assumes a constant deep water formation rate of $0.5 \mathrm{~Sv}$; the second scenario assumes a reduced deep water formation rate $(0.1 \mathrm{~Sv})$ after 1980 . We use these two scenarios; because, based on tracer simulations, Schlosser et al. [1991] and Bönisch and Schlosser [1995] describe that compared to the 1970s, deep water formations rates in the 1980 s were reduced by about $80 \%$. Here we use the model results to extend the estimates of the deep water formation rates to the early 1990 s.

A cold period at the beginning of the 1950 s was followed by warmer conditions in the late 1950s and early 1960 s (Figure 2 a). This warming period is discussed in greater detail below. During the 1970s, the deep water was cold and the temperature showed only small variations, with minimum values of about $-1.3^{\circ} \mathrm{C}$. In the 1980 s and 1990 s, the temperature increased constantly, reaching $-1.149^{\circ} \mathrm{C}$ by late 1994 .

If we include the GEOSECS data with their relatively large uncertainty in salinity (see Figures $2 \mathrm{a}$ and $2 \mathrm{~b}$ ) as a reference point into the evaluation of the salinity time series, the salinity of the waters below $2000 \mathrm{~m}$ depth was the same in 1972 and 1981 with values of about
34.890. In the $1980 \mathrm{~s}$ and $1990 \mathrm{~s}$, the salinity increased in parallel with the temperature increase. The year to year changes are very small $(<0.001)$ and hard to detect. However, the general trend is very clear. In 1994, the mean salinity of the waters below $2000 \mathrm{~m}$ depth reached a value of 34.899, representing an increase of 0.009 over a period of 14 years.

Significant levels of CFCs were already present in the deep water in 1982 at the time of the first survey (Figures. $2 \mathrm{c}$ and $2 \mathrm{~d}$ ). In the deep water, CFC 11 concentrations were $0.76 \mathrm{pmol} \mathrm{kg}^{-1}$, and CFC 12 concentrations were $0.39 \mathrm{pmol} \mathrm{kg}^{-1}$. Since then, the mean concentrations showed only a slight increase, to $0.91 \mathrm{pmol} \mathrm{kg}^{-1}$ (CFC 11) and to $0.45 \mathrm{pmol} \mathrm{kg}^{-1}$ (CFC 12) in 1994. For comparison, the surface concentrations increased from $4.2 \mathrm{pmol} \mathrm{kg}^{-1}$ in 1982 to $6.6 \mathrm{pmol} \mathrm{kg}^{-1}$ in 1994 (CFC 11) and from $1.9 \mathrm{pmol} \mathrm{kg}^{-1}$ in 1982 to $3.1 \mathrm{pmol} \mathrm{kg}^{-1}$ in 1994 (CFC 12). While the surface concentrations increased by about $60 \%$, the concentrations in the deep water increased by less than $20 \%$ over the same period.

The mean tritium concentrations in 1972 were about 1.39 TU (Figure 2 e). By 1980, this value had decreased to $1.17 \mathrm{TU}$. This tritium decrease in the deep water accelerated during the 1980 s and 1990s. In 1988, the tritium concentration reached $0.86 \mathrm{TU}$, and by the end of 1994 it was $0.63 \mathrm{TU}$. For evaluating long-term trends, the concentrations of the radioactive tritium isotope have to be corrected for radioactive decay. In this study, the tritium concentrations are corrected to January 1,1981 . These decay-corrected tritium values increased from $0.84 \mathrm{TU}$ in 1972 to $1.15 \mathrm{TU}$ in 1980 (Fig- 

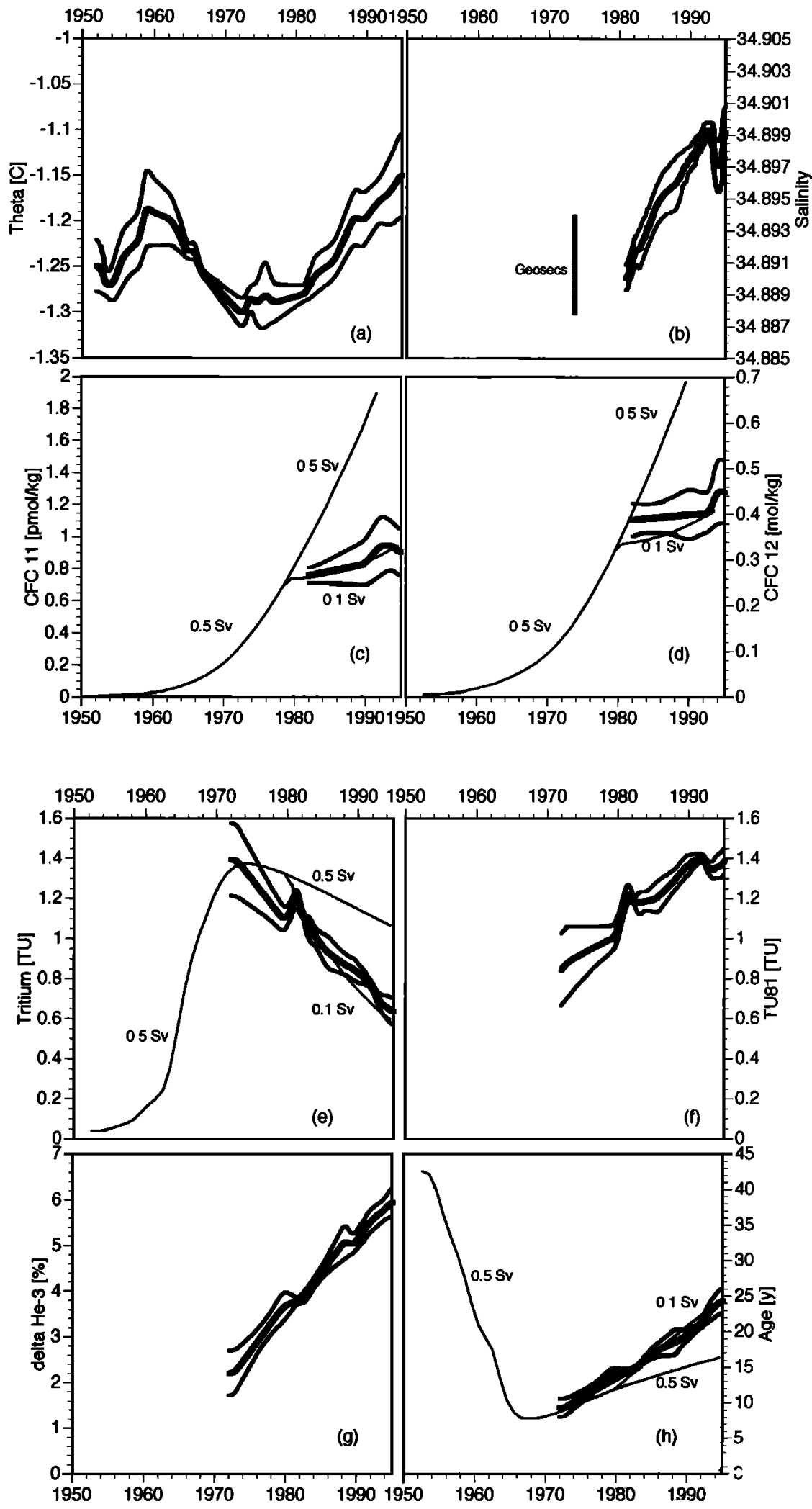

Figure 2. Depth-weighted mean values and $1 \sigma$ standard deviations of (a) theta, (b) salinity, (c) CFC 11, (d) CFC 12, (e) tritium, (f) TU 81, (g) $\delta^{3} \mathrm{He}$, and (h) tritium $/{ }^{3} \mathrm{He}$ age between $2000 \mathrm{~m}$ and the bottom in the central Greenland Sea versus time calculated from the time series in Plate 1. Results of model simulations by Bönisch and Schlosser [1995] for 0.5 Sv deep water formation before 1980 and $0.1 \mathrm{~Sv}$ and $0.5 \mathrm{~Sv}$ in the 1980s and 1990s are indicated where available. 
ure $3 \mathrm{f}$ ). Between 1980 and 1985 , the values increased only slightly to $1.20 \mathrm{TU}$. By 1991 , the decay-corrected tritium had increased to $1.39 \mathrm{TU}$. Between 1991 and the end of the time series in late 1994, no further tritium increase in the deep water of the Greenland Sea was observed.

The decay of tritium is reflected in a $\delta^{3} \mathrm{He}$ increase from $2.2 \%$ in 1972 to $5.9 \%$ in 1994 (Figure $2 \mathrm{~g}$ ) and a resulting tritium $/{ }^{3} \mathrm{He}$ age increase from 9.3 years in 1972 to 14.3 years in 1980 and 24.4 years in 1994 (Figure $2 \mathrm{~h}$ ).

All transient tracer concentrations observed in the deep water of the central Greenland Sea were high during the 1970s and early 1980 s, at the time of the initial measurements. These high transient tracer concentrations indicate recent renewal by waters which were in contact with the atmosphere (the source of the tracers). During the 1980s and early 1990s, the CFC and the decay-corrected tritium concentrations increased slowly. We do not have CFC data from the 1970s; however, the decay-corrected tritium increase in the 1980s and early 1990s was much slower than in the 1970s. This indicates that the influence of water which was in contact with the atmosphere decreased during the 1980 s and early 1990 s compared to the 1970 s. For a quantitative interpretation, the measurements have to be compared to model results. For this purpose, we use the box model of Bönisch and Schlosser [1995]. Figure 2 demonstrates that our new observations remain consistent with deep water formation rates of $0.5 \mathrm{~Sv}$ in the 1970s, followed by a reduced deep water formation rate of $0.1 \mathrm{~Sv}$ beginning in 1980 and continuing through 1994. Note that the model was tuned to a time series of tracer data ending in 1989 [Bönisch and Schlosser, 1995]. However, the transient tracer data from the early 1990 s, published here for the first time, continue to fall on the evolution predicted by the model for a $0.1-\mathrm{Sv}$ deep water formation rate. This means that the general conditions for renewing the water column between $2000 \mathrm{~m}$ and the bottom did not change significantly over the period of 14 years between 1980 and 1994 . Only at the end of the 1980s, an increase in the decay-corrected tritium concentration suggests a short period of 1 or 2 years with increased deep water formation rates (if we assume constant supply of Eurasian Basin Deep Water and Norwegian Sea Deep Water, see below). The CFCs show a slight concentration increase at about the same time, but, within the uncertainties of the measurements, this increase is not significant. Neither the model nor the data are sensitive enough to quantify this short increase in deep water formation in the central Greenland Sea.

4.1.2. Temporal evolution of the properties. For an adequate interpretation of the temperature and salinity trends, we have to perform a water mass analysis. This analysis is also used to examine the processes behind the observed temporal changes. Figure 3 shows the temporal evolution of the decay-corrected tritium/ $\Theta$ correlation, as well as the $\Theta /$ salinity and the CFC $11 / \Theta$ correlations. Also shown are the properties of possible sources of the deep water ( $2000 \mathrm{~m}$ depth to the bottom) in the 1980s. The deep water in the central Greenland Sea is formed by a mixture of water convected from the upper water column, presented as Greenland Sea Surface Water (GSSW), and water advected from the deep Norwegian Sea (Norwegian Sea Deep Water (NSDW)) and the Arctic Ocean (Eurasian Basin Deep Water (EBDW) [Heinze et al., 1990]; Aagaard et al., 1991]; [Rhein, 1991]; [Schott et al, 1993]; [Bönisch and Schlosser, 1995]). As mentioned earlier, deep convection occurs only during winter [Visbeck et al., 1995]. Because the time series does not include the seasonal cycle due to lack of data, we use the $\Theta / S$ characteristics observed by Schott et al. [1993] during deep convection in the Greenland Sea to characterize winter conditions of the surface water. Figures $3 \mathrm{a}$ and $3 \mathrm{~b}$ indicate that the water found in the lower water column of the central Greenland Gyre had higher transient tracer concentrations than all the other deep waters in this region.

The TU81/ $\Theta$ plot is shown in Figure 3 a. In 1950, the tritium concentration of all waters was practically 0 (about $0.2 \mathrm{TU}$ in surface waters [Dreisigacker and Roether, 1978]) and 0.03 TU in the deep water [Bönisch and Schlosser, 1995]). In the surface waters, the tritium concentrations increased rapidly during the $1950 \mathrm{~s}$ and 1960s due to the atmospheric nuclear weapon tests and declined since. Since the deep water of the central Greenland Gyre contained a significant component of recently ventilated near-surface water, its tritium concentration followed the increase of the surface waters, although at a lower rate. This is evident from Figure 3 a for the time between 1950 and 1981 . For this period, the TU81/ $\Theta$ ratio of the deep water in the Greenland Sea does not fall on a mixing line between surface water and the deep waters in the $1980 \mathrm{~s}$, because the initial (1950, marked in Figure 3 a) tritium concentration of the deep water was practically zero and has to be taken into account as one end-member of the mixing diagram for the following reasons. Since water with high tracer concentrations mixed into the deep water over time, even the decay-corrected tritium concentration of the deep water which was tracer-free in 1950 changed continuously. The tracer concentrations increased due to the addition of near-surface water with high tracer concentrations. The initially tracer-free deep water from 1950 has therefore to be taken into account as one end-member of the mixing diagram. The tritium concentration in the deep water never reached equilibrium with the supplying waters.

Although the tritium concentration of the surface water was still much higher (about $5 \mathrm{TU}$, see Plate $1 \mathrm{~d}$ ) than that of the deep water at the beginning of the 1980s, the decay-corrected tritium increase in the deep water nearly stopped at the same time, as its temperature started to increase. Figure 3 a suggests that this is caused by increased relative contributions of NSDW and EBDW. During the 1980s and early 1990s, the CFC 11/ $\Theta$ characteristics (Figure $3 b$ ) showed the same behavior as the TU81/ $\Theta$ characteristics. The dashed lines in Figures $3 \mathrm{a}$ and $3 \mathrm{~b}$ indicate the proposed evolution of the tracer/ $\Theta$ characteristics, if no water with 

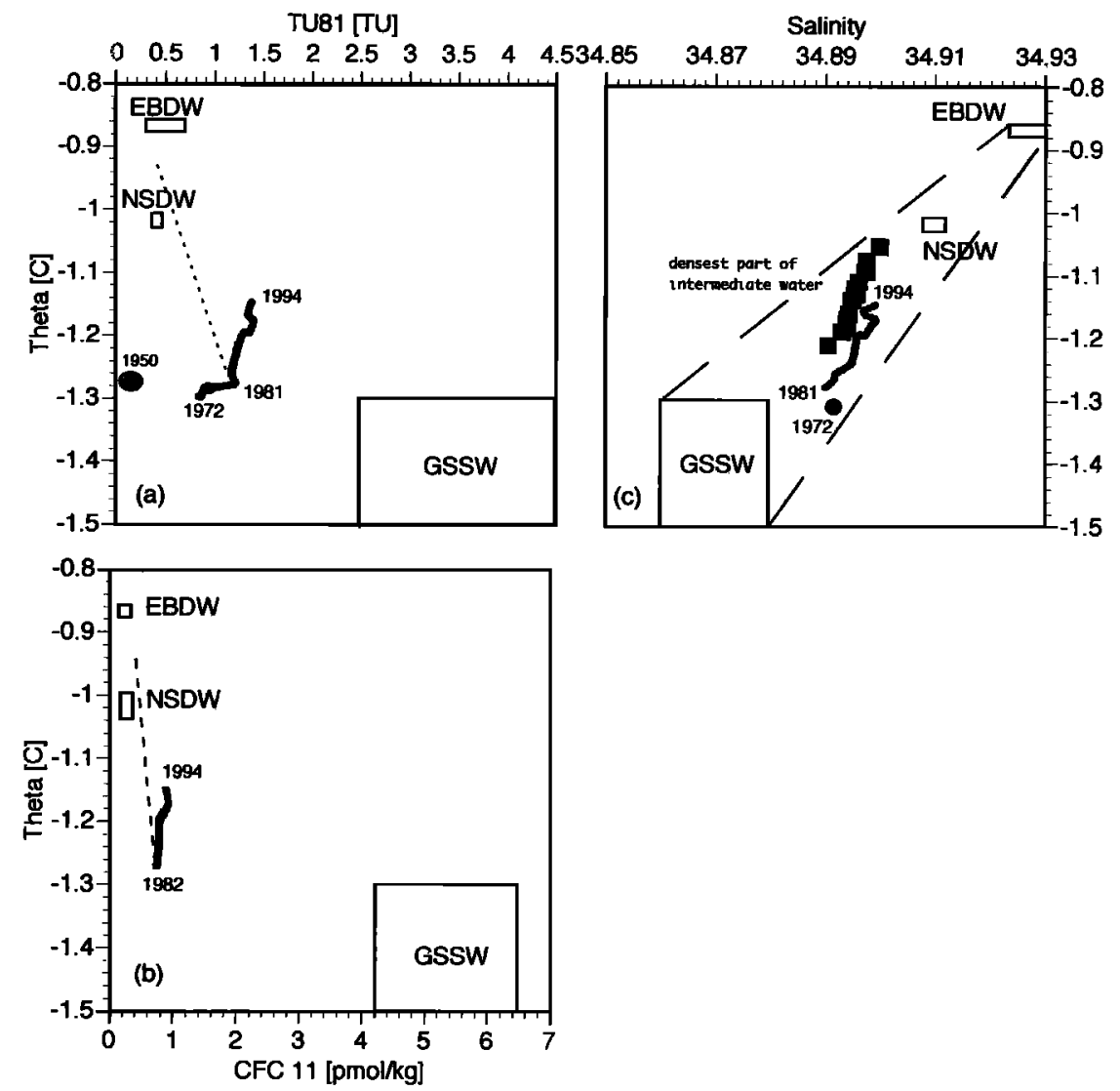

Figure 3. (a) TU81/ $\Theta$, (b) CFC 11/ $\Theta$, and (c) $\Theta / \mathrm{S}$ plot of the depth-weighted mean values from Figure 2 in the central Greenland Sea between $2000 \mathrm{~m}$ and the bottom. Also indicated are the properties of GSSW, EBDW, and NSDW in the 1980s and a mixing line between the deep water value in 1980 and a mean value of EBDW and NSDW in Figures $3 \mathrm{a}$ and $3 \mathrm{~b}$. Additionally indicated in Figure $3 \mathrm{a}$ is the presumable ratio of the deep water in 1950 . In Figure $3 \mathrm{c}$, the possible mixing domain between GSSW, EBDW, and NSDW is marked. Also shown is the time dependent $\Theta / S$ characteristic of the densest $\left(\sigma_{2}>37.45\right)$ part of the intermediate water.

higher transient tracer concentrations contributed to the formation of the deep water during the 1980s and 1990s. Since the properties of the deep water did not follow this line, we conclude that water with higher transient tracer concentrations continued to contribute to the deep water in the central Greenland Sea between 1980 and 1994. Since the deep water of the central Greenland Sea has higher transient tracer concentrations than the deep waters of the adjacent basins contributing to its formation (Norwegian Sea and Eurasian Basin), this water can only originate from the overlying water column of the Greenland Gyre. The contribution of such water was predicted by the tracer balances published by Schlosser et al. [1991] and Bönisch and Schlosser [1995]. However, this water does not necessarily have to originate directly from the surface as implied by their model; it might well be derived from intermediate depths (see discussion below). The simple box model applied by Bönisch and Schlosser [1995] for interpretation of the evolution of the tracer data of the deep water cannot distinguish if the deep water was renewed by near-surface water or intermediate water.

The $\theta / \mathrm{S}$ characteristics of the deep water underwent little change between 1972 and 1981 (Figure $3 \mathrm{c}$ ).
The $\Theta / S$ characteristics were in a quasi-steady state with the source waters. The dashed lines indicate the possible mixing domain between GSSW, EBDW, and NSDW. In the 1980s, the $\Theta / S$ characteristics moved toward those of EBDW and NSDW, that is, the deep water became warmer and more saline. The relative contribution of GSSW decreased, causing the relative contributions of EBDW and NSDW to the deep water of the Greenland Sea to increase. Figure $3 c$ also shows the evolution of the $\Theta / \mathrm{S}$ characteristics of the most dense $\left(\sigma_{2}>37.45\right)$ part of the overlying intermediate water of the central Greenland Sea. The temporal evolution of the $\Theta / S$ characteristics of the deep water in the $1980 \mathrm{~s}$ and 1990s could also be caused by mixing with water from the intermediate layer, EBDW, and NSDW. By the end of 1994, the $\Theta / S$ characteristics of the deep water were still changing; no new quasi-steady state had been reached.

All data indicate a change in the process of deep water formation in the Greenland Sea at around 1980. The transient tracers clearly demonstrate that water with relatively high transient tracer concentrations still contributed in the deep water formation in the 1980s and 1990 s, but at a much lower rate than in the period be- 


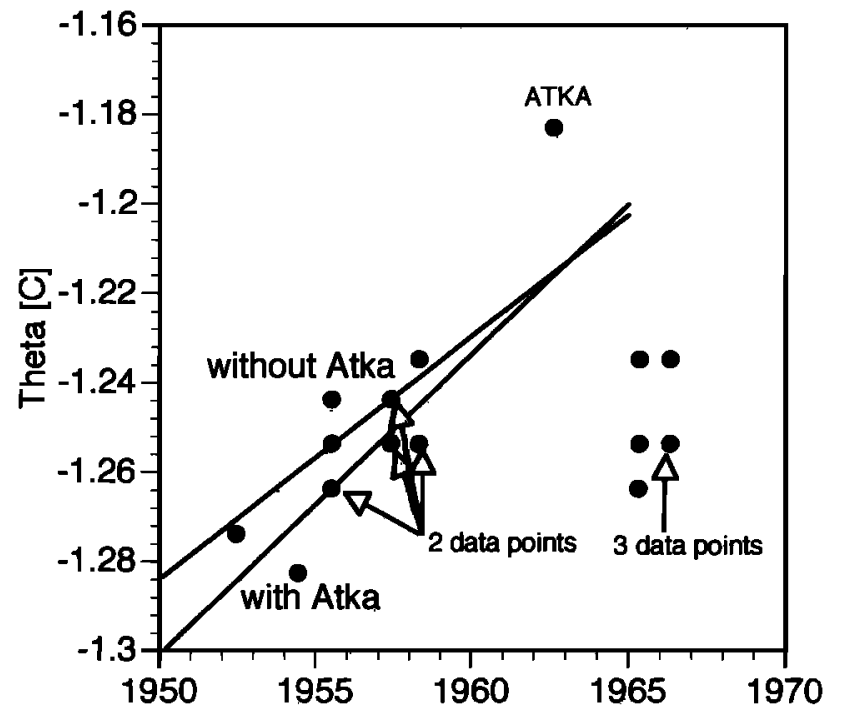

Figure 4. All direct temperature observations between 2900 and $3100 \mathrm{~m}$ depth between 1952 and 1966 , and the linear fit of the data between 1952 and 1962 including and excluding the Atka 1962 cruise. The value of the Atka 1962 cruise is possibly too high. However, even without the Atka value, a temperature increase of $0.005^{\circ} \mathrm{C}$ per year is observed.

fore 1980. This water must originate from the upper or intermediate water column of the Greenland Sea.

4.1.3. Warming in the late 1950s. In this section, we examine the warming of the deep water in the 1950s. Figure 4 shows all temperature observations from the depth range between 2900 and $3100 \mathrm{~m}$ between 1952 and 1966 and linear fits of the data up to 1962 including and excluding the Atka 1962 cruise. The Atka data point lies above the trend of the earlier and later data. Extrapolation excluding the Atka data predicts a temperature of $-1.225^{\circ} \mathrm{C}$ for 1962 , instead of $-1.183^{\circ} \mathrm{C}$ as observed. However, a significant warming trend of $0.005 \pm 0.001^{\circ} \mathrm{C}$ per year is present even excluding the Atka data point. Therefore we conclude that a warming of the deep water of the central Greenland Sea took place in the late 1950s, but it may not have been as pronounced as suggested by the Atka data.

Since the temperature increase in the lower layer in the 1980s and 1990s coincides with a period of lower deep water formation rates as demonstrated by the transient tracer time series, the temperature increase observed during the late 1950 s may also reflect an earlier period of decreased deep water formation. Since we do not have transient tracer observations from the 1950 s, we have to examine the available data for their significance for this period. Due to its half-life of 269 years, ${ }^{39} \mathrm{Ar}$ data indicate the average deep water formation rate of the last several decades preceding their sampling date. The very limited ${ }^{39} \mathrm{Ar}$ data obtained in 1981 by Smethie et al. [1986] (88\% modern) for the deep Greenland Sea suggest that average deep water formation rates were high preceding 1981 (the time of observation). However, since the ${ }^{39} \mathrm{Ar}$ data average over a long period of time, they do not exclude short peri- ods of low deep water formation rates. Bönisch and Schlosser [1995] point out that the tritium concentrations of the deep water observed during the 1970 s require a high deep water formation rate since at least 1965. Therefore we speculate on the basis of admittedly limited data that deep water formation rates of about $0.5 \mathrm{~Sv}$ reflect the normal conditions for the Greenland Sea for the past several decades, but for periods lasting several years deep water formation rates could have been lower preceding 1965. The period of low deep water formation rates in the 1980s and early 1990s was very likely not the only event of this kind. For example, deep water formation rates were probably low in the late 1950 s as well.

\subsection{Intermediate Water $(200-2000 \mathrm{~m})$}

The most remarkable feature observed in the intermediate water $(200-2000 \mathrm{~m})$ is the decrease in density between 1981 and 1994 (Plate 1c). Figure 5 shows the
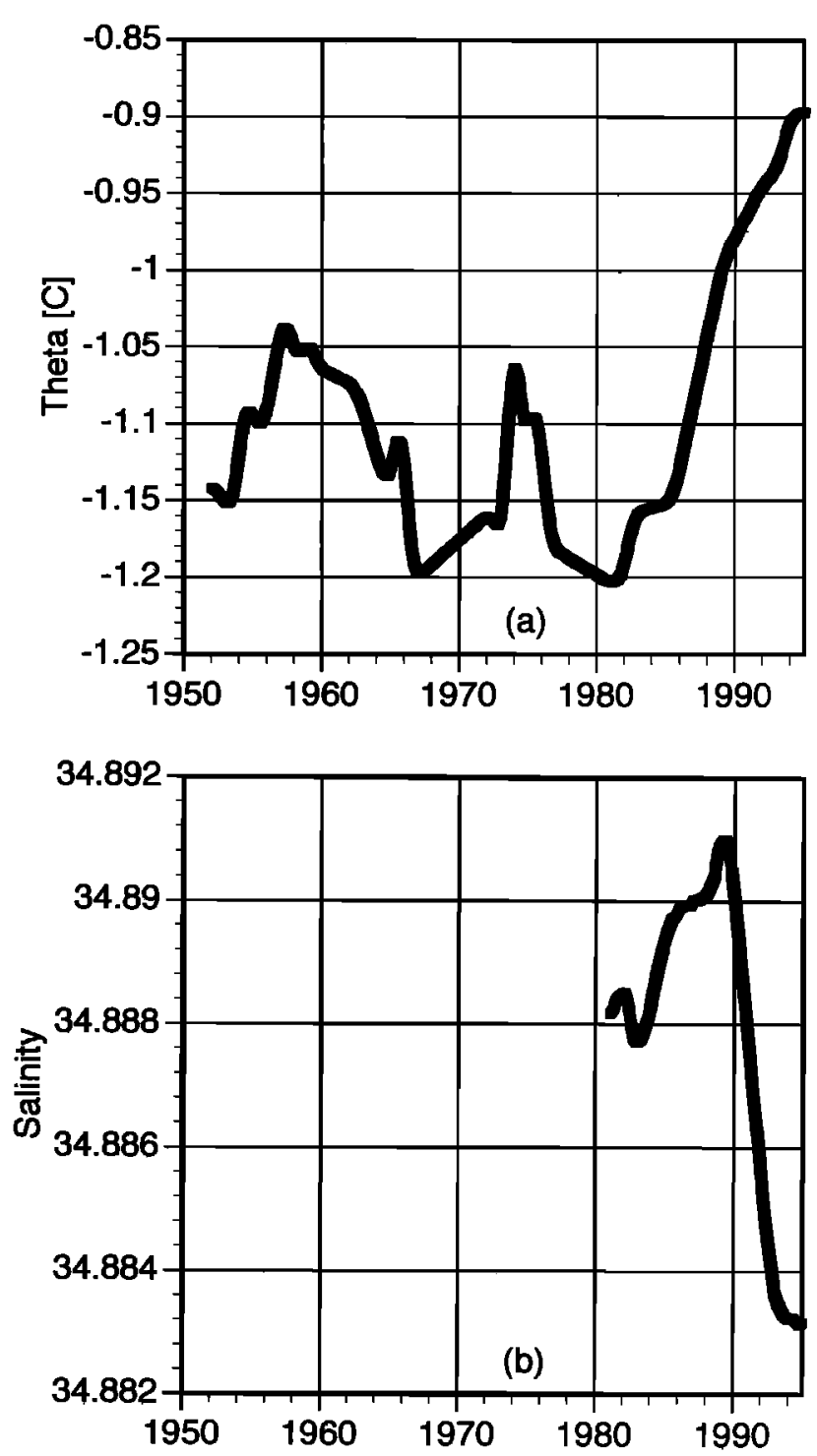

Figure 5. Depth-weighted mean values of (a) $\Theta$ and (b) salinity from the depth range between 200 and $2000 \mathrm{~m}$ in the central Greenland Sea versus time. 
evolution of the average salinity and temperature values in this layer. Before 1980, the temperatures ranged between roughly -1.05 and $-1.2^{\circ} \mathrm{C}$. Since 1981 , the temperature increased continuously, reaching $-0.9^{\circ} \mathrm{C}$ in 1994 (Figure 5 a).

Although vertical salinity variations in this layer can be large, varying from 34.855 at $200 \mathrm{~m}$ depth to 34.898 at $2000 \mathrm{~m}$ depth at the same station (station 1359 of the Johan Hjort cruise in 1991), the total salt content indicated by the mean value of the gridded data shows only small variations in time (Figure $5 \mathrm{~b}$ ). An increase from 34.888 in 1981 to 34.891 in 1989 is followed by a decrease, reaching 34.883 in 1994. Formation of a 25cm-thick layer of sea ice (with zero salinity) from water with a salinity of $\mathbf{3 4 . 8 7}$ (winter surface salinity observed by Schott et al. [1993]) would reset the average salinity from 34.883 to 34.888 . Since the spatial salinity variations are high (up to 0.043 ) compared to the observed temporal changes ( 0.005 in 13 years), these temporal variations may not be significant.

The total heat content of the intermediate water (calculated relative to the pressure and salinity dependent freezing point) increased from $6.93 \times 10^{4} \mathrm{MJ} \mathrm{m}^{-2}$ in 1981 to $7.17 \times 10^{4} \mathrm{MJ} \mathrm{m}^{-2}$ in 1994 , an increase of 0.24 x $10^{4} \mathrm{MJ} \mathrm{m}^{-2}$, which represents an average net heating rate of $5.3 \mathrm{~W} \mathrm{~m}^{-2}$ (Figure 6). Cooling rates during deep convection are about 150 to $200 \mathrm{~W} \mathrm{~m}^{-2}$ [Visbeck et al., 1995] and persist usually for about 2 months each year. Therefore the total heat loss per year typically would not exceed $0.12 \times 10^{4} \mathrm{MJ} \mathrm{m}^{-2}$. This implies that it would take about 2 years of cooling and deep convection to remove the heat accumulated over 13 years.

Deep water formation rates decreased in 1980 (see above). NSDW, however, is formed as a mixture of water from the deep Greenland Sea and EBDW [Swift and Koltermann, 1988]. If the production of new deep water is not high enough to balance the implied loss

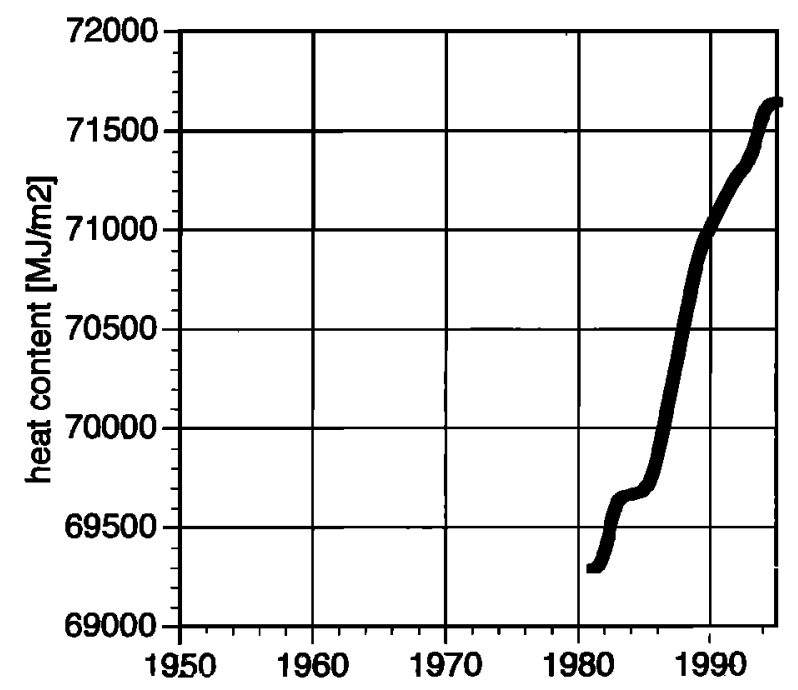

Figure 6. Total heat content calculated relative to the salinity and depth dependent freezing point of the water column between 200 and $2000 \mathrm{~m}$ in the central Greenland Sea versus time. of deep water required for continued NSDW formation, the most dense $\left(\sigma_{2}>37.45\right)$ fraction of the intermediate water may sink below $2000 \mathrm{~m}$ and enter or mix with the deep layer. Since intermediate waters have higher transient tracer concentrations than the deep water (e.g., about $1.2 \mathrm{pmol} \mathrm{kg}^{-1}$ CFC 11 at $800 \mathrm{~m}$ depth and about $0.8 \mathrm{pmol} \mathrm{kg}^{-1}$ at $2700 \mathrm{~m}$ depth in 1982 ), the roughly constant transient tracer concentrations in the deep water observed during the 1980s and 1990s (Figures 2 and 3) could also be explained as a mixing product of the most dense intermediate water and the deep waters from the Norwegian Sea and the Arctic Ocean (see Figure 3). Such a scenario would be consistent with the observed density decrease in the intermediate water (Plate $1 \mathrm{c}$ ).

Figure 7 a shows the deepening of the 37.33, 37.43, and 37.45 isopycnals over time; Figures $7 b, 7 c$, and $7 \mathrm{~d}$ show the development of the CFC 11 concentrations, the decay-corrected tritium concentrations, and the tritium $/{ }^{3} \mathrm{He}$ age on these isopycnals, respectively. The uncertainties in these quantities are relatively high (the transient tracer values had to be interpolated onto isopycnals). On the highest density isopycnal (37.45), the decay-corrected ${ }^{3} \mathrm{H}$ concentration decreased only slightly and the CFC 11 concentration remained more or less constant over time, whereas the tritium $/{ }^{3} \mathrm{He}$ age increased from 7 years in 1981 to 20 years in 1994, i.e., at a 1:1 ratio with the calendar year. This indicates that on this isopycnal either no mixing with older or younger water occurred or the mixing was exactly balanced, a behavior very similar to that observed in the deepest water. On the 37.43 isopycnal, the transient tracer concentrations decreased and the tritium $/{ }^{3} \mathrm{He}$ age increased, suggesting lateral advection of older water or vertical mixing with underlying water. Constant decaycorrected tritium concentrations and increasing CFC concentrations indicate a strong influence of younger water on the 37.33 isopycnal. In contrast to the CFCs, the tritium concentration on this isopycnal remains constant as a result of the declining surface concentrations.

\subsection{Upper Waters $(0-200 \mathrm{~m})$}

The evolution of the transient tracer distributions in the surface layer of the central Greenland Sea is consistent with the trend in their atmospheric concentrations (increasing CFCs, decreasing tritium, constant $\delta^{3} \mathrm{He}$ ). Due to a lack of seasonally resolved data, possible changes in the surface layer that may trigger or prevent deep convection during winter time cannot be addressed by this study. However, since all available observations since 1988 were made in November, the salinities can be compared. The average salinity of the upper layer increased from 34.72 in 1991 to 34.85 in 1994. Since the average salinity of the intermediate water $(200-2000 \mathrm{~m})$ decreased from 34.886 in 1991 to 34.883 in 1994 (see Figure $5 \mathrm{~b}$ ), the salinity difference between the surface and the intermediate water decreased as well from 0.16 in 1991 to 0.03 in 1994, destratifying the water column and making convection in the future more likely. 

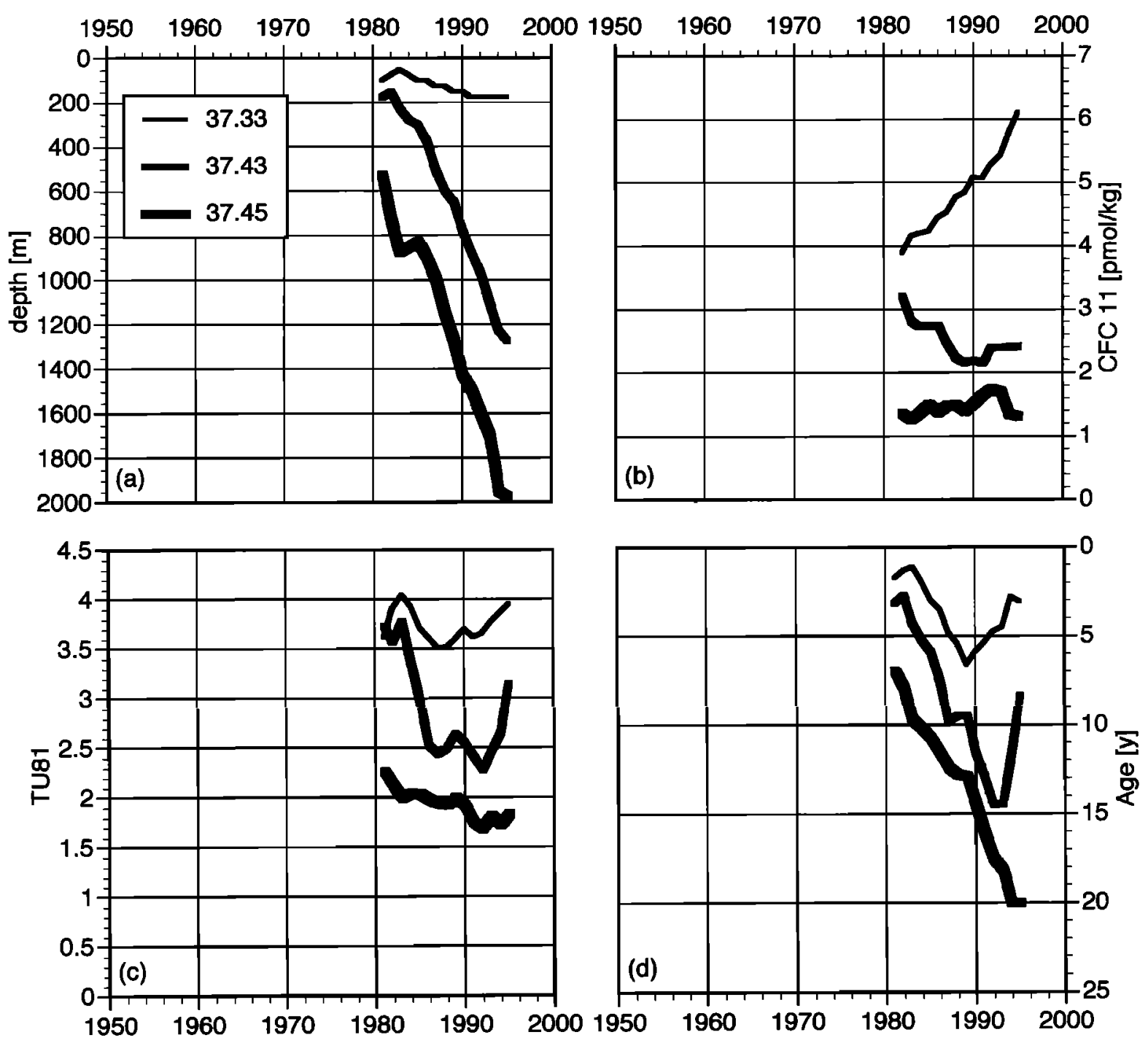

Figure 7. (a) Depth of the $37.33,37.43$, and 37.45 isopycnals in the central Greenland Sea versus time. (b) CFC 11, (c) TU81, and (d) tritium $/{ }^{3} \mathrm{He}$ age along the $37.33,37.43$, and 37.45 isopycnals in the central Greenland Sea versus time.

\section{Conclusions}

Hydrographic conditions were highly variable in the Greenland Gyre during the past few decades. High tracer concentrations in the deep water observed in the 1970 s and early 1980 s were associated with low salinities and temperatures and indicate high deep water formation rates. Constant CFC and decay-corrected tritium concentrations in the 1980 s and early 1990 s were associated with increasing salinities and temperatures in the deep water and reflect a decreased surface.contribution and larger relative contributions of EBDW and NSDW to the deep water in the Greenland Sea. However, the transient tracer observations in the $1980 \mathrm{~s}$ and early 1990 s indicate that water with higher transient tracer concentrations continued to contribute to the deep water formation during this period, although at a lower rate. This water can only originate from the overlying water column of the Greenland Sea. It may probably have been intermediate water. The decrease in deep water formation rates in the 1980 s and early 1990 s was very likely not the first event of this kind; the warming of the deep water in the late 1950s suggests a similar event.

Although the intermediate water is inhomogeneous with respect to all parameters, the mean temperature showed only small variations between 1952 and 1980 . Between 1981 and 1994, however, the layer between 200 and $2000 \mathrm{~m}$ depth warmed continuously, while the average salinity showed only small variations. This warming is equivalent to a net heating rate of about $5 \mathrm{~W} \mathrm{~m}^{-2}$. The heat accumulated over a period of 13 years could be removed by two winters of intensive cooling. The density decrease in the intermediate water can be explained by sinking of the most dense part of the intermediate water into the deep water below $2000 \mathrm{~m}$. This scenario 
is consistent with the evolution of hydrographic parameters, as well as transient tracers, in the deep and intermediate water.

The time series available for this study do not include the seasonal cycles and therefore generally do not allow statements about the surface waters. However, the possible comparison of the surface salinities between 1991 and 1994 shows a steady increase over this period, and the reduced salinity difference between the surface and the intermediate water destratifies the water column and makes more rigorous convection more likely.

The combination of hydrographic and transient tracers is useful to determine long-term trends of deep water formation rates and processes. If annual highquality time series data are available, it is possible to detect climatically important changes that occur on timescales of several years to decades.

Acknowledgments. We are grateful to Jerry Fries, Jim Happell, Fred Menzia, and Craig Neill who performed the CFC analyses and collected the He and tritium samples. The officers, crews, and scientific staff of the R/V Johan Hjort provided excellent technical support. We acknowledge the long-term commitment of the Institute of Marine Research, Bergen, in providing ship time and infrastructure necessary for the annual cruises of the the R/V Johan Hjort to the Greenland Sea. We are thankful to K.P. Koltermann for helpful discussions and to Francesco Rey for his assistance and advice. The Lamont-Doherty Earth Observatory tritium/helium laboratory was established through a generous grant by the W. M. Keck Foundation. Financial support by the National Oceanic and Atmospheric Administration (NOAA) under grants NA46GPO112 and NA16RC0512-01, by the Office of Naval Research (ONR) under grants N00014-90-J-1362 and N00014-94-I-0507, by the U.S. Department of Energy under contract DE-ACO2$76 \mathrm{CH} 00016$, and by the Deutsche Forschungsgemeinschaft is gratefully acknowledged. L DEO contribution 5649.

\section{References}

Aagaard,K., J.H. Swift and E.C. Carmack, Thermohaline Circulation in the Arctic Mediterranean Seas. J. Geophys. Res., 90, 4833-4846, 1985.

Aagaard, K., E. Fahrbach, J. Meincke, and J.H. Swift, Saline outflow from the Arctic Ocean: Its contributions to the deep waters of the Greenland, Norwegian and Iceland Seas, J. Geophys. Res., 96, 20,433-20,441, 1991.

Benson, B.B., and D. Krause Jr., Isotopic fractionation of helium during solution: A probe of the liquid state, $J$. Solution Chemistry, 9, 895-909, 1980,

Bönisch, G., and P. Schlosser, Deep water formation and exchange rates in the Greenland/Norwegian Seas and the Eurasian Basin of the Arctic Ocean derived from tracer balances, Progr. Oceanogr., 35, 29-52, 1995.

Bourke, R.H., R.G. Paquette, R.F. Blythe, and M.D. Stone, On the deep and bottom waters of the Greenland Sea from summer 1989 and 1990 data, J. Geophys. Res., 98, 4629-4638, 1993.

Bullister, J.L., and R.F. Weiss, Anthropogenic chlorofluoromethanes in the Greenland and Norwegian Seas, Science, 221, 265-268, 1983.

Clarke, A., J.H. Swift, J.C. Reid, and K.P. Koltermann, The formation of the Greenland Sea Deep Water: Double diffusion or deep convection, Deep Sea Res., Part A, 37, 1385-1424, 1990.
Clarke, W.B., W.J. Jenkins and Z. Top, Determination of tritium by mass spectrometric measurement of ${ }^{3} \mathrm{He}$, Int. J. Appl. Radiat. Isot., 27, 515-522, 1976.

Cunnold, D.M., P.J. Fraser, R.F. Weiss, R.G. Prinn, P.G. Simmonds, B.R. Miller, F.N. Alyea and A.J. Crawford, Global trends and annual releases of $\mathrm{CCl}_{3} \mathrm{~F}$ and $\mathrm{CCl}_{2} \mathrm{~F}_{2}$ estimated from ALE/GAGE and other measurements from July 1978 to June 1991, J. Geophys. Res., 99, 1107-1126, 1994.

Dreisigacker, E., and W. Roether, Tritium and ${ }^{90} \mathrm{Sr}$ in North Atlantic surface water, Earth Planet. Sci. Lett., 38, 301$312,1978$.

Happell, J. and D.W.R. Wallace, Gravimetric preparation of gas phase standards containing volatile halogenated compounds for oceanographic applications. Deep Sea Research, in press, 1997.

Happell, J.D., D.W.R. Wallace, K.D. Wills, R.J. Wilke and C.C. Neill, A purge-and-trap capillary column gas chromatographic method for the measurement of halocarbons in water and air, Informal Rep. 63227, 19 pp., Brookhaven National Laboratory, Upton, N.Y., 1996.

Heinze, C., P. Schlosser, K.P. Koltermann and J. Meincke, A tracer study of the deep water renewal in the European Polar Seas. Deep Sea Res., Part A, 37, 1425-1453, 1990.

Koltermann, K.P., and H. Lüthje, Hydrographischer Atlas der Grönland und nördlichen Norwegischen See (1979 1987). (Hydrographic atlas of the Greenland and northern Norwegian seas), Deutsches Hydrographisches Institut, Hamburg, 1989.

Ludin, A., R. Weppernig, G. Bönisch, and P. Schlosser, Mass spectrometric measurement of helium isotopes and tritium in water samples, in Tracer Oceanography, Geophys. Monogr. Ser., AGU, Washington, D.C., in press, 1997.

Meincke J., S. Jonsson, and J.H. Swift, Variability of convective conditions in the Greenland Sea, ICES Mar. Sci. Symp., 195, 32-39, 1992.

Nansen, F., Northern waters: Captain Roald Amundsen's Oceanographic Observations in the Arctic Seas in 1901, Skr. Nor. Akad. I, Mat. Naturv. Klasse, 3, 145 pp., 1906.

National Oceanographic Data Center, CD ROMs NODC-02 and NODC-03: Global Ocean Temperature and Salinity Profiles, Washington, D.C., 1991.

Östlund, H.G., and C. Grall, Arctic tritium: 1973 - 1991, Tritium Lab. Data Rep. 19, Rosenstiel School of Mar. and Atmos. Sci., Univ. of Miami, Miami, Fla., 1993.

Östlund, H.G., H. Craig, W. S. Broecker, and D. Spencer (Eds.), GEOSECS Atlantic, Pacific and Indian Ocean Expeditions; Shorebased Data and Graphics, vol. 7, 230 pp., Nat. Sci. Found., Washington, D.C., 1987.

Quadfasel, D., and J. Meincke, Note on the thermal structure on the Greenland Gyre, Deep Sea Res., Part A, 34, 1883-1888, 1987.

Rhein, M., Ventilation rates of the Greenland and Norwegian Seas derived from the distribution of the chlorofluoromethanes F-11 and F-12, Deep Sea Res., 38, 485-503, 1991.

Schlosser, P., Tritium $/{ }^{3} \mathrm{He}$ dating of waters in natural systems, in: Isotopes of Noble Gases as Tracers in Environmental Studies, 123-145, Int. Atom. Energy Agency, Vienna, 1992.

Schlosser, P., G. Bönisch, M. Rhein, and R. Bayer, Reduction of deepwater formation in the Greenland Sea during the 1980s: Evidence from tracer data. Science, 251, 10541056, 1991.

Schlosser, P., G. Bönisch, B. Kromer, H.H. Loosli, B. Bühler, R. Bayer, G. Bonani, and K.P. Koltermann, Mid 1980s distribution of tritium, ${ }^{3} \mathrm{He},{ }^{14} \mathrm{C}$, and ${ }^{39} \mathrm{Ar}$ in the Greenland/Norwegian Seas and the Nansen Basin of the Arctic 
Ocean: Implications for large-scale circulation patterns, Progr. Oceanogr., 35, 1-28, 1995.

Schott, F., M. Visbeck, and J. Fischer, Observations of vertical currents and convection in the central Greenland Sea during the winter of $1988-1989$, J. Geophys. Res., 98, 14,401-14,421, 1993.

Smethie, W.M., Jr., H.G. Östlund, and H.H. Loosli, Ventilation of the deep Greenland and Norwegian Seas: Evidence from krypton-85, tritium, carbon-14 and argon-39. Deep Sea Res., Part A, 33, 675-703.

Swift, J.H., and K. Aagaard, Seasonal transition and water mass formation in the Iceland and Greenland Seas. Deep Sea Res., Part $A_{1,}$ 28, 1107-1129, 1981.

Swift, J.H., and K.P. Koltermann, The origin of Norwegian Sea Deep Water, J. Geophys. Res., 99, 3563-3569, 1988.

Swift, J.H., T. Takahashi, and H.D.Livingston, The contribution of the Greenland and Barents seas to the deep water of the Arctic Ocean, J. Geophys. Res., 88, 5981-5986, 1983.

Unterweger, M.P., B.M. Coursey, F.J. Schima, and W.B. Mann, Preparation and calibration of the 1978 National Bureau of Standards tritiated-water standards, Int. J. Appl. Radiat. Isot., 31, 611-614, 1980.

Visbeck, M., J. Fischer, and F. Schott, Preconditioning the Greenland Sea for deep convection: Ice formation and drift, J. Geophys. Res., 100, 18,489-18,502, 1995.
Wallace, D.W.R., A. Putzka, and P. Beining, Carbon tetrachloride and chlorofluorocarbons in the South Atlantic Ocean, $19^{\circ} \mathrm{S}$. J. Geophys. Res., 99, 7803-7819, 1994.

Weiss, W., and W. Roether, The rates of tritium input to the world oceans. Earth Planet. Sci. Lett., 49, 435-446, 1980.

Woods Hole Oceanographic Institution, Helium Isot. Lab, Data Release 3.0, 1981 Results TTO, Woods Hole, Mass., 1989.

Johan Blindheim, Institute of Marine Research, PO Box 1870 Nordnes, N-5024 Bergen, Norway.

Gerhard Bönisch and P. Schlosser, Lamont-Doherty Earth Observatory, Palisades, NY 10964. (e-mail: peters@ldeo.columbia.edu)

J. L. Bullister, Pacific Marine Environmental Laboratory, National Oceanographic and Atmospheric Administration, 7600 Sand Point Way, N.E., Seattle, WA 98115.

D. W. R. Wallace, Oceanographic and Atmospheric Sciences Division, Department of Applied Science, Brookhaven National Laboratory, P.O. Box 5000, Upton, NY 11973-5000.

(Received August 27, 1996; revised February 10, 1997; accepted March 5, 1997.) 